\title{
CARBAZOLE: AN UPDATED PROFILE OF BIOLOGICAL ACTIVITIES
}

\author{
Babita Rawat', Sucheta1, Shivali Rahi' ${ }^{2}$ and Arpana Rana ${ }^{2 \star}$ \\ ${ }^{1}$ K.R. Mangalam University, Sohna Road, Gurgaon, Haryana-122 103, India. \\ ${ }^{2}$ Advanced Institute of Pharmacy, 70 km Delhi-Mathura Road, \\ Palwal, Haryana-121 105, India.
}

\begin{abstract}
Past several years report the significance of the heterocyclic nucleus carbazole and its derivatives. Carbazole skeleton is key pharmacophore for many biologically active compounds in synthetic as well as natural. The present review compiles biological profile of carbazole and its derivatives from 2012 till now.
\end{abstract}

Keywords: Carbazole, biological activity, anticancer, antibacterial and antiproliferative.

\section{INTRODUCTION}

Heterocyclic chemistry acted as a boon in drugdiscovery and there are many pharmacologically active heterocyclic compounds. Out of which nitrogen containing heterocyclic compounds remained the favorite of researchers.

Carbazoles are nitrogen containing aromatic heterocyclic compounds ${ }^{1}$. Structure of carbazoles possess desirable electronic and charge transport properties as well as large $\pi$ conjugate system and the various functional groups that can be easily introduced into the structurally rigid carbazolyl ring ${ }^{2-4}$.

Presence of particular characteristics in the structure are responsible for potential applications of carbazole and its derivatives in the field of chemistry including photoelectrical materials, dyes etc ${ }^{5}$.

Carbazole skeleton $(1)^{6}$ is the key element for many biological active compounds including synthetic and natural products for example carbazomycins, class of antibiotics have carbazole framework carbazomycin A and B inhibits growth of phytopathagenic fungi and have antibacterial and anti-yeast activities ${ }^{7-10}$. other major example is of carbazole alkaloids naturally occurring heterocycles with carbazole skeleton isolated from the Rutaceae family, which has properties like stimulant, stomachic, febrifuge, analgesic also used in the treatment of diarrhea, dysentery, insect bites and show antibacterial activity ${ }^{10-12}$.

Many other derivatives of alkaloids such as ellipticine and 9-methylelipticine has anticancer activities ${ }^{13}$. Synthetic carbazoles and its derivatives has supramolecular recognition show pharmacological activities like antitumor ${ }^{14}$ antimicrobial, anticonvulsants ${ }^{15}$, antihistaminic, antioxidative, anti-inflammatory, antidiabetic, psychotropic, antiproliferative etc. ${ }^{16-20}$. Keeping in mind the vast therapeutic potential of carbazole, the present review focuses on the recent progress, from 2012 till now, in knowledge on various biological activities of carbazole and its derivatives.

\section{Anti-Alzheimer}

Choubdar N, et al., (2019) ${ }^{21}$ has synthesized a series of compounds comprising the carbazole backbone linked to the benzyl piperazine, benzyl piperidine, pyridine, quinoline, isoquinolinemoiety through an aliphatic linker and evaluated as cholinesterase inhibitors. The synthesized compound (2) showed IC50 values of $0.11-36.5 \mu \mathrm{M}$ and $0.02-98.6 \mu \mathrm{M}$ against acetyl and butyrylcholinesterase (AChE and BuChE), respectively. The ligandprotein docking stimulations and kinetic studies revealed that compound (2) could bind effectively to the peripheral anionic binding site 
(PAS) and anionic site of the enzyme with mixed-type inhibition. Compound (2) was the most potent compound against AChE and BuChE and showed acceptable inhibition potency for self and AChE-induced A $A 1-42$ aggregation. Moreover, compounds (2) could significantly protect $\mathrm{PC} 12$ cell against $\mathrm{H}_{2} \mathrm{O}_{2}-$ induced toxicity. The results suggested that the compounds (2) could be considered as a promising multi-functional agent for further drug discovery development against Alzheimer's disease.

Ghobadian R., et al., (2018) ${ }^{22}$ have synthesized and designed a new serious of carbazoleBenzyl Pyridine derivatives and evaluated as butyrylcholinesterase (BChE) inhibitors. In vitro assay revealed that all of the derivatives has selective and potent anti-BChE. $3-((9 \mathrm{H}-$ carbazole-9-yl)methyl)-1-(4-

chlorobenzyl)pyridine-1-ium

chloride compound (3) had the most potent anti-BChE activity (IC50 value $=0.073 \mu \mathrm{M})$, the highest BChE selectivity and mixed-type inhibition. Docking study revealed that compound (3) interacted with the peripheral site, the choline binding site, catalytic site and the acyl pocket of BChE. Physicochemical properties were accurate to lipinski's rule. In addition, compound (3) demonstrated neuroprotective activity at $10 \mu \mathrm{M}$. this compound can also inhibit AChE-induced and self-induced Aßdpeptide aggregation at concentration of $100 \mu \mathrm{M}$ and $10 \mu \mathrm{M}$ respectively. The in-vivo study showed that compound (3) in $10 \mathrm{mg} / \mathrm{kg}$ increased the time spent in target quadrant in the probe day and decreased mean training period scape latency in rats. All results suggest that new sets of potent selective inhibitors of AChE have a therapeutic potential for the treatment of $A D$.

\section{Antibacterial activity}

Dabrovolskas K., et al $(2020)^{23}$ has synthesized several compounds 3-cyano- $9 \mathrm{H}$ carbazole (4), 3-iodo- $9 \mathrm{H}$-carbazole (5) and 3,6-Dibromo- $9 H$-carbazole (6) by known methods, and their antibacterial activity was evaluated against Bacillissubstilisand Eschericha coli using a disk diffusion method. The disk diffusion method revealed that tested compounds showed antibacterial activity against tested strains, they inhibited the growth of bacteria at various concentration, from 31.25 to $250 \mu \mathrm{g} / \mathrm{ml}$. 3-cyano- $9 H$ carbazole, 3-iodo-9H-carbazole and 3,6Dibromo- $9 \mathrm{H}$-carbazole showed a stronger antibacterial activity against Bacillus subtilis compared to the reference drug amoxiciline. Whereas,1,3.6- Tribromo-9- $\mathrm{H}$-carbazole (7) showed a stronger activity against Escherichia coli.
Venktapathy K., et al $(2020)^{24}$ have been design and the eco-benign synthesis of new class of carbazolyl-1,4-dihydropyridine $(1,4-$ CDHP) (8) and carbazolyl-1,-8dioxodecahydroacridine (9) (CAD) derivatives via a three-component coupling reaction of substituted carbazole aldehydes, ethyl acetoacetate/dimedone, and ammonium acetate under solvent-free conditions at 112 ${ }^{\circ} \mathrm{C}$ to $115^{\circ} \mathrm{C}$. they also reports an efficient one pot synthesis of new class of carbazolylpolyhydroquinoline (CPQ) derivatives via a four-component coupling reaction of substituted ethyl acetoacetate, dimedone, ammonium acetate, and carbazole aldehydes in acetonitrile/water medium (3:1) at $73^{\circ} \mathrm{C}$ to $75{ }^{\circ} \mathrm{C}$ in moderate yields. The synthesized heterocyclic compound (8 and 9) showed antibacterial activity against pathogenic strains of both Gram-negative and Gram-positive bacteria. Minimum inhibitory concentration (MIC) of the active compounds was evaluated by macrodilution method.

Guhanathan S., et al (2019) ${ }^{25}$ has synthesized bromoderivative $\mathrm{N}$-bromoacetyl-5,8-dibromo 5,6-dihydro(3,2-a) (10) and N-bromoacetyl-2,6dibromo-1,2,3,4-tetrahydrocarbazole (11) of carbazole compounds by free radical bromination using 4-bromophenylhydrazine and various reactant such as alpha-tetralone cyclohexanone and cyclopentanone with suitable solvent such as carbontetrachloride. The solvent selected must be suitable for reaction condition and temperature. Brominated carbazole derivatives(10) and (11) were further acetylated using bromoacetylbromide in DMF as a solvent. The synthesized compound (10) \& (11) found to have excellent antibacterial activity.

Pattanashetty S.H., et al $(2018)^{26}$ has synthesized $\mathrm{N}$-phenylacetamide-functionalized (12a-j) derivatives under conventional method in excellent yields. $\mathrm{N}$-substituted carbazole exhibited potent antibacterial activity against $S$. aereus, B. subtilis, $E$. coli, $P$. aeraginosa. Among all tested compound (12a), (12e), (12g) and $(12 \mathrm{~h})$ exhibited antibacterial activity with MICs ranging from 2.0 to $0.25 \mu \mathrm{g} / \mathrm{ml}$

Wang pei-yi, et al., $(2017)^{27}$ has synthesized various pyridinium-functionalized carbazole derivatives that were constructed by coupling the key fragments of carbazole skeleton and pyridinium nucleus in a single molecular architecture. Antibacterial bioassays revealed that some of the title compounds displayed impressive bioactivities against plant pathogens such as Xanthomonasoryzaepv, Oryzae,ralstolniasolanacearunm, and Xanthomonasaxonopodispv. Citri with minimal EC50 values of up to $0.4,0.3$, and $0.3 \mathrm{mg} / \mathrm{L}$, respectively. These bioactivities were achieved 
by systematically tuning and optimizing bridging linker, alkyl length of the tailor, and substituents on the carbazole scaffold. Compared with the bioactivity of the lead compound (13), antibacterial efficacy dramatically increased by approximately 13-, 104- and 21- fold. This finding suggested that these compounds can serve as new lead compound (13) in research on antibacterial chemotherapy.

Parthiban $\mathrm{P}$, et al.,(2014) $)^{28}$ has designed and synthesized a series of $\mathrm{N}$-((5,6,7,8-tetrahydro carbazol-9-yl-methyl) substituted amines $(14,15)$ and evaluation as a antibacterial activity against E. coli, P.aeruginosa, K. pneumonia, S. typhii, Staphylococcus aures, amoxicillin used as standard drug and antifungal activity against $C$. Albicans and $A$. Niger at 50 and $100 \mu \mathrm{g} / \mathrm{ml}$ level.

Griseofulvin (50 and $100 \mu \mathrm{g} / \mathrm{ml})$ act as antifungal activity C. Albicans and A. Niger. According to this compound $(14,15)$ showed better antifungal activity against $100 \mu \mathrm{g} / \mathrm{ml}$ concentration, all the compounds showed will antifungal activity compound moderate activity against $\mathrm{S}$. Aureus and exhibited more activity all bacteria.

Sharma D., et al $(2014)^{29}$ was designed a novel series 5-[(9H-carbazol-9-yl)methyl $]-N$ [substituted phenyl)(piperazin-1-yl)methyl]1,3,4-0xadiazol-2-amines (16a-0) derivatives was synthesized by starting with carbazole, which on reaction with ethyl chloroacetate yielded ethyl 2-(9H-carbazole-9-yl)acetate. All the derivatives were evaluated for their antibacterial activity. Compound 16a, 16d, $16 e, 16 n$ showed antibacterial activity.

Kaushik K., et al (2012) ${ }^{30}$ synthesized a series of carbazole on reaction with chloroacetyl chloride afforded $N^{9}$-(chloroacetyl)-carbazole (17) which on treatment with hydrazine hydrate has yielded $\mathrm{N}^{9}$-(hydrazinocetyl)-carbazole, condensation with various aromatic aldehydes afforded $\quad \mathrm{N}^{9}$ (arylidenehydrazinoacetyl)carbazoles, which on cycloaddition with isatin in the presence of ammonium acetate yielded 1-carbazole-9-yl-2-(substitutedphenyl)-1,4-

dihydroimidazo-[4,5-b]indol 1-yl-amino)ethanone (17a-k). All the synthesized compound were evaluated for their antibacterial activity. Compound were screened for in-vitro antibacterial activity against the two-gram positive bacterial strains like staphylococcus aureus and bacillus subtilis and two-gram negative bacterial strain like Pseudomonas aeruginosa and Escherichia coli. All the newly synthesized compound (17d) and (17e) showed most potent antibacterial activity against all bacterial strain.

\section{Anticancer activity}

Liu Y., et al (2020) ${ }^{31}$ was formulatedand investigated the structure-activity relationship of novel $N$-substituted carbazole sulfonamide derivatives with improved physicochemical properties. Most of these new compounds displayed good aqueous solubility. Certain molecules presented strong in vitro antiproliferative and in vivo antitumor activity. Relative to the control, $50 \mathrm{mg} / \mathrm{kg}$ compound (18)reduced human HepG2 xenograft mouse tumor growth by $54.5 \%$ and its efficacy was comparable to that of CA-4P. They also developed a novel synthetic method for 7hydroxy-substituted carbazole sulfonamides. Compared with the control, $25 \mathrm{mg} / \mathrm{kg}$ compound (18) inhibited human HepG2 xenograft mouse tumor growth by $71.7 \%$ and was more potent than $50 \mathrm{mg} / \mathrm{kg}$ CA-4P with only $50 \%$ tumor shrinkage efficacy. Among the three water- soluble carbazole sulfonamide derivatives formulated in the present study. Compound (18)displayed the most effective tumor growth inhibition in vivo and merit further investigation as potential antitumor agent cancer therapy.

Rao Durga B.V., et al (2019) 32 has synthesized a series of isoxazole-thiadiazole linked carbazole derivatives (19a-j). The products are tested for their anticancer activity against human cancer cell line: MCF-7 (breast), A549 (lungs), DU-145 (prostste), and MDA MB-231 (breast) by using MTT assay and etoposide as a reference drug. The accumulated data indicate that most of the compound 19b, 19c,19d, 19f, 19g exhibited very strong anticancer activity.

Jiang H., Zhang W.J., et. al $(2018)^{33}$ has synthesized a series of carbazole-rhodanine conjugates and evaluated for their topoisomerase II inhibition potency as well as cytotoxicity against a panel of four human cancer cell lines.Among, these compounds,20a, 20b, 20g, possessed topoisomerase II inhibition potency at $20 \mu \mathrm{g}$. Mechanism study revealed that these compounds may function as topo II catalytic inhibitors. It was found that the electron withdrawing groups on the phenyl ring of compound (20a) played an important role on enhancing both enzyme inhibition and cytotoxicity.

VlaarC.P., et al (2018) ${ }^{34}$ has been synthesized a new series of carbazole derivatives. Based on the efficacy of EHop-016as an inhibitor of migration and Rac1 activation. Cytotoxic and anti-migratory effects of these compounds were evaluated in MCF-7 and MDA-MB-231 breast cancer cell lines. Preliminary investigation of their anticancer demonstrated that several compounds have moderate antiproliferative effects on cancer cell lines 
with $\mathrm{Gl}_{50}$ values in the range of $13-50 \mu \mathrm{M}$. Furthermore, compounds $(21,22)$ inhibit migration activity of metastatic cell line MDAMtB-231 by $32 \%$ and 34\%, respectively. Compound (22) was shown to inhibit activation of the Rho GTPase Rac1 by $55 \%$ at $250 \mathrm{nMin}$ both MDA-MB-231 and MDA-MB-435 cell lines. Compared with the $\mathrm{IC}_{50}$ of Rac1 inhibition by lead compound EHop-016 of $1.1 \mu \mathrm{M}$, compound (12) demonstrates $4 \mathrm{X}$ improved in vitro efficacy.

You X., et al (2018) ${ }^{35}$ to synthesized a set of structurally diverse synthetic carbazoles was screened for their anticancer activities. According to structure-activity relationship studies, carbazoles with an $\mathrm{N}$-substituted sulfonyl group exhibited better anticancer activity. Moreover, compound (23) was discovered to show the most potent anticancer effects on capan-2 cells by inducing apoptosis and cell cycle arrest in G2/M phase. Finally, the in vivo study demonstrated that (23) prevented that the tumor growth in PANC-1 and capan-2 xenograft models without apparent toxicity.

Kumar N., et al (2016) ${ }^{36}$ have designed series of such active compounds i.e. 2- [(4,5dihydro-2-substituted phenyl) imidazole-1ylamino]-1-(9H-carbazole-9-yl) ethanone and 2-(9H-carbazole-9-yl)- $N$-[\{(4-substituted

phenyl) (piperazine-1-yl)\}methyl] acetohydrazide were synthesized. All the synthesized compounds were screened for their invitro anticancer activity against human breast cancer cell line (MCF 7) by sulphorodamine $B(S R B)$ assay method. $\mathrm{Gl}_{50}$ was majored by using $10,20,40$ and $80 \mu \mathrm{g} / \mathrm{ml}$ concentration of tested compound along with the standard i.e. Adriamycine. Result revealed that the tested compound was comparable to Adriamycine having $\mathrm{Gl}_{50}<10 \mu \mathrm{g} / \mathrm{ml}$. compound $(24,25)$ was found to be most active among all the tested compounds. Carbazole in combination with other heterocycles might be used as a lead for finding of the potent anticancer agents. Substitution at $9^{\text {th }}$ position also increases the therapeutic value of carbazole toward the treatment of cancer.

Li. B., et al., (2013) ${ }^{37}$ has synthesized a series of pyrido[3,2- $\alpha$ ] carbazole derivatives and all these compounds evaluated for their antitumor activity against human lung cancer A549 cells and colon cancer HT29 cells. The intermediates are successfully synthesized and ethyl 2-(3- bromopyridine -2-yl) acetate by Knoevenagel condensation intramolecular heck-type reaction and this is a novel efficient synthetic approach to the core scaffold of the target compounds. Theses target compounds have shown an interesting antitumor profile towards the tested cell lines with $\mathrm{IC}_{50}$ values ranging from $0.007 \mu \mathrm{M}$ to $4.45 \mu \mathrm{M}$. Among all the compounds synthesized, compound (26, 27) showed higher potency.

Gu. W., et al (2014) ${ }^{38}$ had designed and synthesized a series of new carbazole derivatives of ursolic acid. All the synthesized compounds were evaluated for anti-cytotoxic activity. In vitro cytotoxicity of these compounds is assayed against two human tumor cell lines (SMMC-7721) and HepG2 using MTT colorimetric method. Among all these compounds (28e) was found to be the most potent compound with $\mathrm{IC}_{50}$ values of 1.08 \pm 0.22 and $1.26 \pm 0.17 \mu \mathrm{M}$ against SMMC7721 and HepG2 cells, respectively, comparable to those of doxorubicin. In addition, compound (28) showed reduced cytotoxicity against noncancerous LO2 cells with $\mathrm{IC}_{50}$ value of $5.75 \pm 0.48 \mu \mathrm{M}$.

Haider. N., et al (2014) ${ }^{39}$ has synthesized new b-Fused carbazolesN'-(9-bromo-1-chloro-5methyl-6H-pyridazino[4,5-b]carbazole-4-yl)-

$\mathrm{N}, \mathrm{N}$-diethylpropane-1,3-diamine(29) and 8Bromo-2-[3-(diethylamino)propyl]-4methylpyrrolo[3,4-b]carbazole-1,3(2H,5H)dione(30). Interestingly, the two compounds showed marked differences in cell-type specially, with 30 being most active against HTB65 and (29) against the SW480 line.

Howorko. J.R., et al $(2013)^{40}$ has synthesized 1-substituted pyrido[4,3-b]carbazole derivative. All of them were tested in vitro for their anticancer activity on three tumor cell lines:CCRF/CEM(T lymphoblast leukemia), A549 (lung adenocarcinoma), and MCF7 (breast cancer). Among all compounds, compound $(31,32,33)$ were showed strongest anticancer activity.

Kalplancikli. Z.A., et al $(2012)^{41}$ had synthesized some $\mathrm{N}$-(9-Ethyl-9-H-carbazole-3$y$ l)-2-(phenoxy)acetamide derivatives for their anticytoxic activity. The title compounds were obtained by reacting 2-chloro- $\mathrm{N}$-(9-ethyl- $9 \mathrm{H}$ carbazole-3-yl) acetamide with some substituted phenols. All the synthesized compound (34) was studied for their cytotoxic effects MTT assay, and it was seen that (34) had the lowest cytotoxic activity against $\mathrm{NIH} / 3 \mathrm{~T} 3$ cells.

\section{Anti-inflammatory activity}

Muniyappan. G., et al $(2016)^{42}$ was synthesized a novel 4-hydroxycarbazole derivatives. The reaction involved $O$-alkylation of 4-hydroxycarbazole using methyl 5bromovalerate. All the synthesized compounds were screened for their in vitro antiinflammatory activity. Among the synthesized compounds, compound (35a, 35b and 35c) were found to show good anti-inflammatory 
activities against the standard drug diclofenac sodium.

Surendiran. T., (2015) ${ }^{43}$ has synthesized the compounds isoxazolinyl and pyrazolinyl1,2,3,4-tetrhydrocarbazoles were individually prepared by using chalconyl-1,2,3,4tetrahydrocarbazoles (36, 37) with condensation of hydroxylamine hydrate and hydrazine hydrate respectively. All titled compounds were evaluated against antiinflammatory activities by using carrageenan induced edema model in rates.

Bandgar.B.P., et al (2012) ${ }^{44}$ has synthesized a novel series of 3-(substituted)-aryl-5-(9-methyl3-carbazole)-1H-2-pyrazolines(38a-0). All the synthesized compounds were evaluated for their in vitro and in vivo anti-inflammatory activity. Compound (38c) was found to potent inhibitor of the carrageenin induced paw edema in rats. Molecular docking result, along with the biological assay data, suggested that compound (38c) was a potential antiinflammatory agent.

\section{Antimicrobial activity}

Jasass R.S., et al (2018) ${ }^{45}$ has synthesized new derivatives of carbazole incorporated with thiazole moiety via the reaction of carbazole thiosemicarbazone with hydrazonoyl chloride under microwave irradiation. The spectral results and the absorption data proved the postulated structures of the resulting compounds. The staring thiosemicarbazone and compound (39) and (40) were evaluated against two fungi $\mathrm{G}^{+}$bacteria and $\mathrm{G}$ - bacteria. The results obtained explore the high potency of some of the tested compounds compared with the employed standard bactericides and fungicides.

Chakraborty S., et al $(2017)^{46}$ has been synthesized 6-fluoro-1H-carbazole(41), 6fluoro-2-metheyl-1H-carbazole(42), 6-fluoro-3methyl-1H-carbazole(43) and their respective quinone derivatives 6-fluoro- $1 \mathrm{H}$-carbazole1,4(9H)-dione(44), 6-fluoro-2-methyl-1 $\mathrm{H}$ carbazole-1,4(9H)-dione(45) and 6-fluoro-3methyl-1H-carbazole-1,4(9H)-dione(46) have been studied against Escherichia coli (MTCC 42), Bacillus subtilis (MTCC 121), staphylococcus aureus (MTCC 96), Methicillinresistant Staphylococcus aureus (MRSA) and Pseudomonas sp. (MTCC 6199). The experimental results show that methyl substituent at C-2 and C-3 along with electron withdrawing fluorine atom at $\mathrm{C}-6$ in the carbazoloquinone as well as the compound (42 ,43, 45and 46) showed antibacterial activity against MRSA.

Clausen J.D., et al (2017) ${ }^{47}$ has synthesized a carbazole series have been identified as potent fungal plasma membrane proton adenosine triphosphate $\left(\mathrm{H}^{+}\right.$-ATPase) inhibitors with a broad spectrum of antifungal activity. The carbazole compound (47) inhibit the adenosine triphosphate (ATP) hydrolysis activity of the essential fungal $\mathrm{H}^{+}$-ATPase, thereby functionally inhibiting the extrusion of proton and extracellular acidification, processes that are responsible for maintaining high plasma membrane potential. The compound class binds to and inhibits the $\mathrm{H}^{+-}$ ATPase within minutes, leading to fungal death after 1-3h of compound exposure in vitro. The tested compounds are not selective for fungal $\mathrm{H}^{+}$-ATPase, exhibiting an overlap of inhibitory activity with the mammalian protein family of p-type ATPase the sarcoendoplasmic reticulum calcium ATPase ( $\mathrm{CA}^{2+}$-ATPase) and the sodium potassium ATPase $\left(\mathrm{Na}^{+} \mathrm{K}^{+}\right.$ATPase). The ion transport in the p-type ATPases is energized by the conversion of ATP to adenosine diphosphate (ADP) and phosphate and a general inhibitory mechanism mediated by the carbazole derivative could therefore be blocking of the active site. However, biochemical studies show that increased concentration of ATP do not change the inhibitory activity of the carbazoles suggesting they act as allosteric inhibitors. Furthermore, decreased levels of intracellular ATP would suggest that the compounds inhibit the $\mathrm{H}^{+}$-ATPase indirectly, but Candida albicans cells exposed to potent $\mathrm{H}^{+}$-ATPase-inhibitory carbazoles result in increased levels of intracellular ATP, indicating direct inhibition of $\mathrm{H}^{+}$-ATPase.

GluszynskaAgata $(2015)^{48}$ has synthesized new macrocyclic diamides based on carbazole skeleton with thia and oxy-linkage system. Antimicrobial activities of compounds were tested against four human pathogenic bacteria such as Proteus mirabilis, Proteus vulgaris, staphylococcus aureus, and Salmonella typhi.

Antifungal activity of these compounds was also tested against four plants pathogenic fungi such as Rhizoctoniasolani, Macrophominaphaseolina, Curvularialunata and Alternariaalternata. The screening of amides compound (48 and 49) for their biological activity expressed by minimum inhibitory concentration (MIC), was performed in vitro conditions with the use of a control sample $(10 \% \quad$ DMSO $)$ and commercial antibiotics, tetracycline and carbendazim (for plant pathogenic fungi).

The carbazolophanes (48) and (49) exhibited good antibacterial and antifungal activities against all pathogens.

\section{Anti-mycobacterium activity}

Surineni. G., et al (2018) ${ }^{49}$ have been design, synthesis and evaluation of novel series of 
dibenzofuran, dibenzothiophene and $N$-methyl carbazole tethered 2-aminothiazoles and their cinnamamide analogs. 1- pot condensation of $N$-methyl carbazole, dibenzofuran and dibenzothiphene methyl ketone with thiourea in the presence of iodine and Cuo gave respective 2-aminothiazoles 4-6 in a very good yield. Aminothiazoles were further coupled with substituted cinnamic acids using acid amine coupling conditions to give desired cinnamamide analogs 50, 51. In vitro screening of new derivatives against mycobacterium tuberculosis.

Shaikh. Mahamadhanif. S., et al $(2014)^{50}$ has synthesized various substituted carbazolethiazoles(52a-0) by using a molecular hybridization approach. The synthesized compounds were evaluated for their in vitro anti-tubercular activity against Mycobacteriium tuberculosis $\mathrm{H}_{37} \mathrm{Rv}$ strain at the national Institute of Allergy and infectious diseases (Bethesda, MD, USA). Among the tested series, compound (52) (minimum inhibitory concentration $21 \mu \mathrm{M})$ showed the most promising anti-mycobacterial activity. Brief structure activity relationship studies showed that the electron donating groups $\left(\mathrm{OCH}_{3}\right.$ and $\mathrm{OH}$ ), particularly on the phenyl ring of the thiazole motif, had a positive correlation with the anti-mycobacterial activity. In addition, they displayed low cytotoxicity against a mammalian vero cell line using the MTT assay, thereby having a high therapeutic index. This study shows the importance of molecular hybridization and the scope for the development of carbazole thiazole compounds as potential anti-mycobacterial agents.

Yogeeswari. P., et al $(2014)^{51}$ has synthesized a series of novel carbazole tethered pyrrole(53a-i) derivatives were designed by coupling core fragments of antitubercular agents, carbazole and substituted pyrrole in single molecular architecture. The synthesized of new analogues was achieved by $\mathrm{FeCl}_{3}$ mediated one pot three component condensation of 2-nitrovinylcarbazoles with aryl or alkyl amines and dimethylacetylenedicarboxylate (DMAD). All new synthesized compounds were screened for in vitro anti-mycobacterial activity against Mycobacterium tuberculosis H37Rv, Dimethyl 1-(4-fluorophenyl)-4-(9-methyl-9H-carbazole-3yl)-1 $H$-pyrrole-2,3-dicarboxylate (53) was found to be most active with MIC $3.13 \mu \mathrm{g} / \mathrm{ml}$ and has shown low cytotoxicity.

\section{Antiproliferative activity}

Sinicropi. S.M., et al $(2017)^{53}$ have been synthesized carbazole derivatives constitute an interesting class of heterocycles, which showed several pharmaceutical properties and occupied a promising place as antitumor tools in preclinical studies. They target several cellular key-points, e.g. DNA and topoisomerase I and II. The most studied representative, i.e. ellipticine, was introduced in the treatment of metastatic breast cancer. However, because of the onset of dramatic side effects, its use was almost dismissed. Many efforts were made in order to design and synthesized new carbazole derivatives with good activity and reduced side effects. The major goal of the study was to synthesized a series of new $\mathrm{N}$-thioakylcarbazole derivatives with anti-proliferative effects. Compound (54) possess an interesting anti-proliferative against breast and uterine cancer cell lines without affecting non-tumoral cell lines viability. Wang.W., et al $(2016)^{54}$ have been synthesized novel carbazole amino-alcohols as anticancer agents. Among them alkylaminechain-substituted compound (55) showed the most promising antiproliferative activity, with $\mathrm{IC}_{50}$ values in the single- digit micromolar range against two human tumor cell lines. Topoisomerase I (topo I) is likely to be one of the targets of these compounds. Results of comet assays and molecular docking indicate that the representative compounds may act as topo I poisons causing single-strand DNA damage by stabilizing the topo I-DNA cleavage complex. In particular, the most potent compound, 1-(butylamnio)-3-(3,6-dichloro-9-yl) propan-2-ol was shown to be able to induce G2 phase cell cycle arrest and apoptosis in HeLa cells.

\section{Miscellaneous activity Antidiabetic activity}

Adib. M., et al (2019) ${ }^{55}$ have synthesized twenty-three fused carbazole-imidazoles(56-w) and screened as new a-glucosidase inhibitors. All the synthesized fused carbazole-imidazoles were found to be more active than acarbose $\left(\mathrm{IC}_{50}=750.0 \pm 1.5 \mu \mathrm{M}\right)$ against yeast $\alpha-$ glucosidase with $\mathrm{IC}_{50}$ in the range of $74.0 \pm 0.7-$ $298.3 \pm 0,9 \mu \mathrm{M}$. kinetic study of the most potent compound demonstrated that this compound is a competitive inhibitor for a-glucosidase (Ki value $=75 \mu \mathrm{M})$. Furthermore, the in-silico studies of the most potent compounds (56o) and (56v) confirmed that these compounds interacted with the key residues in the active site of $\alpha$-glucosidase

\section{Antimalarial activity}

Kandor V.A., et al (2019)56 have been synthesized a series of carbazole based 1,4benzothiazepine and pyrazoline(57a-f) derivatives were synthesized and the structures of the newly synthesized compounds were confirmed by FT-IR, $1 \mathrm{H}$ 
NMR, 13NMR and mass spectral studies. All new derivatives were screened for their in vitro antimalarial activity. Compound (57a, 57b and 57d) exhibited promising antimalarial activity.

\section{Antioxidative activity}

Dabrovolskas K., et al (2020) ${ }^{57}$ several compounds were synthesized and evaluated antioxidative activity using free 1,1-diphenyl-2picryl-hydrazyl radical scavenging assay and ferric reducing antioxidant power methods. Compound (58) was most potent.

\section{Antiviral}

Caruso. A., et al (2019) have synthesized a series of carbazole derivatives. Reported the Viruses represents the most common cause of infectious disease worldwide and those with rapid propagation high infection rates cause human and animal pandemics. The fastspreading diseases are generally treated with antiviral drugs but, often, drug resistance occurs because of the ability of the pathogens to mutate rapidly and become less susceptible to the treatments. Even though new antiviral compound (59) has been affected, e.g., in HIV (human immunodeficiency virus) HCV (hepatitis $C$ virus) therapeutic areas, the need of dispose of new pharmaceutical tools for the management of infections that still have no treatment is growing interest. In these areas, carbazole represents an important privileged scaffold in drug discovery. Many compounds with a carbazolic core have been developed and some of them have shown antiviral activity. This review provides an overview on some already known carbazole derivatives, pointing the attention on the running progresses in identifying new molecules with carbazolic structure, that have shown interesting and encouraging in vitro and in vivo properties. These drugs may be exploited as valid alternatives in antiviral therapy.

\section{CONCLUSION}

In recent 10 years, numerous carbazole derivatives have been synthesized and subjected to studies with various biological activities. Some of carbazole compounds have a very high activity against many organisms: bacteria, fungi, parasites, or are potential antiinflammatory agents. The antimicrobial and antifungal activities of different compounds, including macrocyclic diamides and azoles based on carbazole skeleton, have been tested against many human pathogenic bacteria and fungi. Some of the compounds showed comparable or even better antibacterial and antifungal properties against tested strains than the reference drugs. 

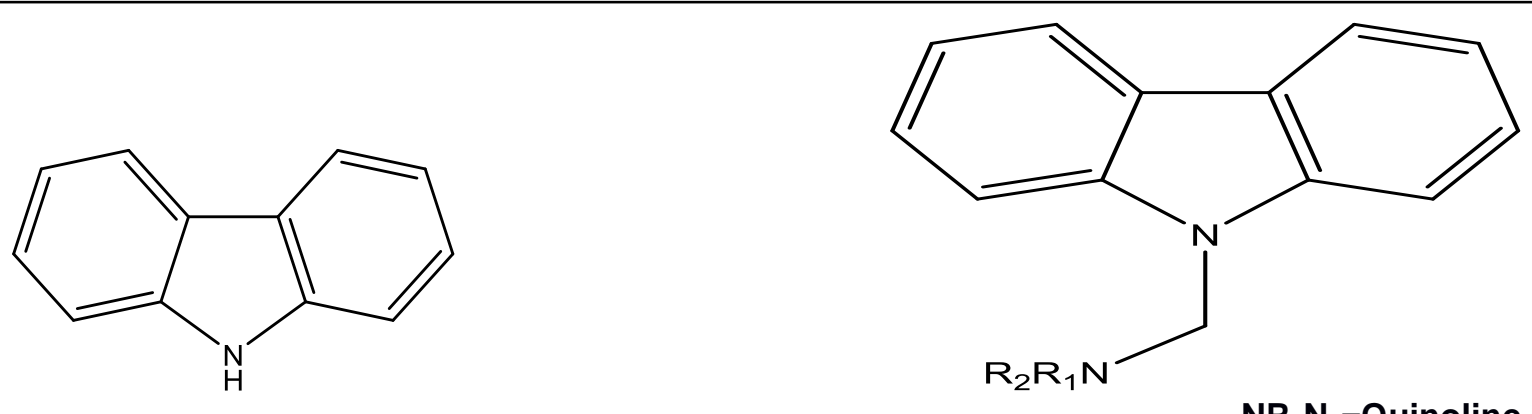

(1) (2)

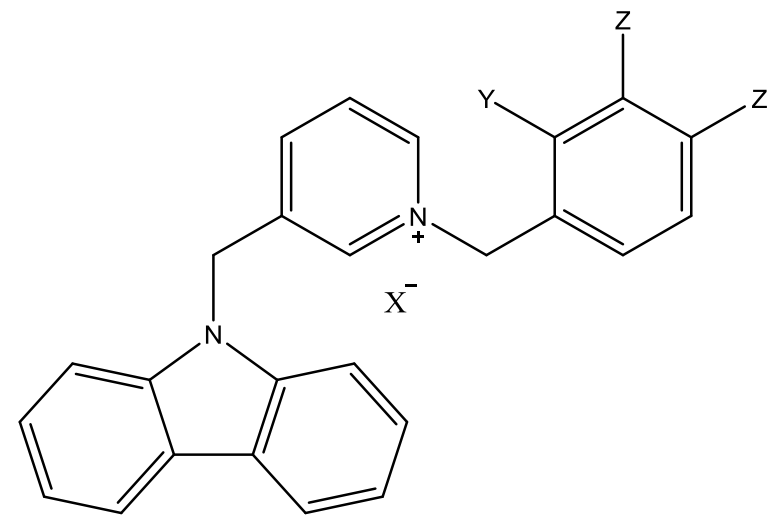

$\mathrm{X}=\mathrm{Cl}, \mathrm{y}=\mathrm{H}, \mathrm{Z}=\mathrm{H}, \mathrm{Z}^{\prime}=\mathrm{Cl}$

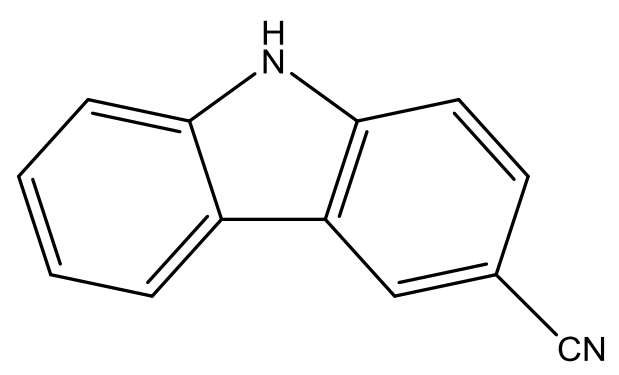

(3)

(4)

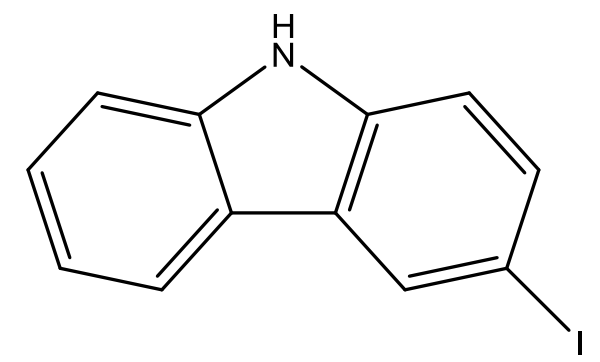

(5)

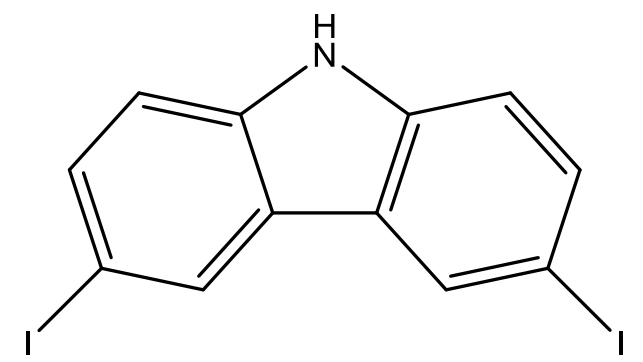

(6) 


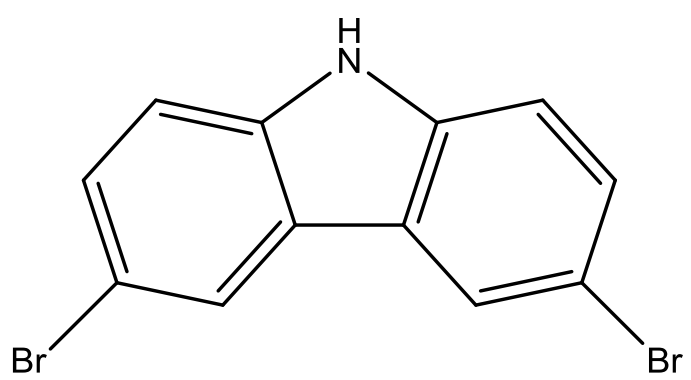

(7)

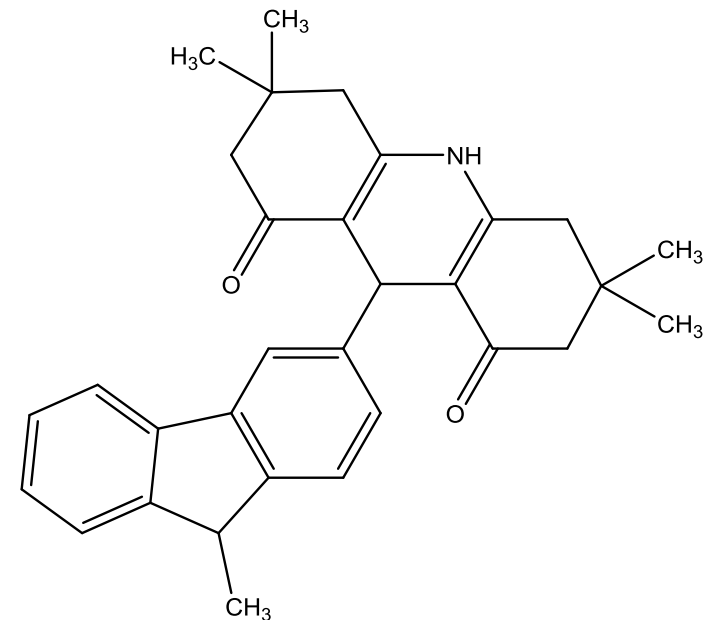

(9)

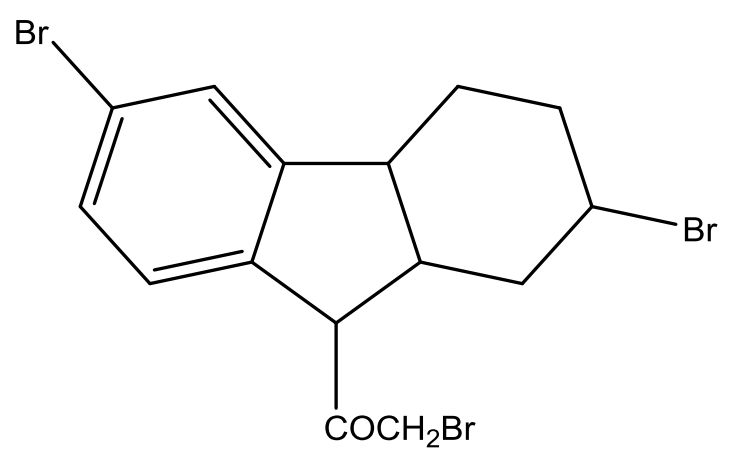

(11)

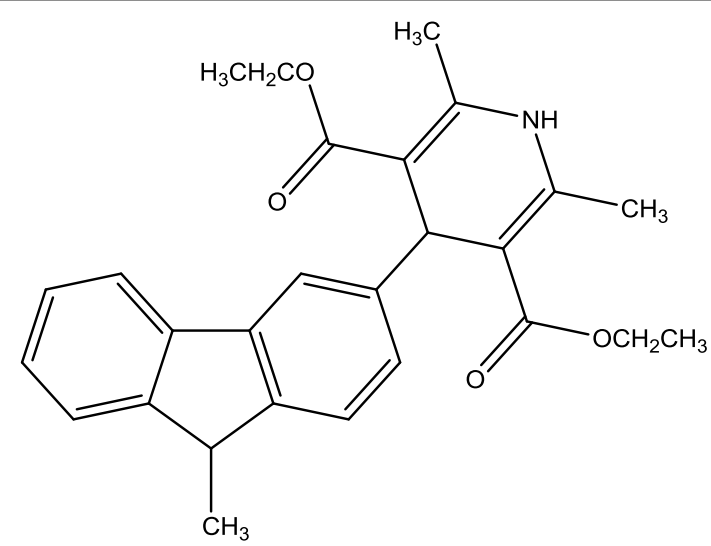

(8)

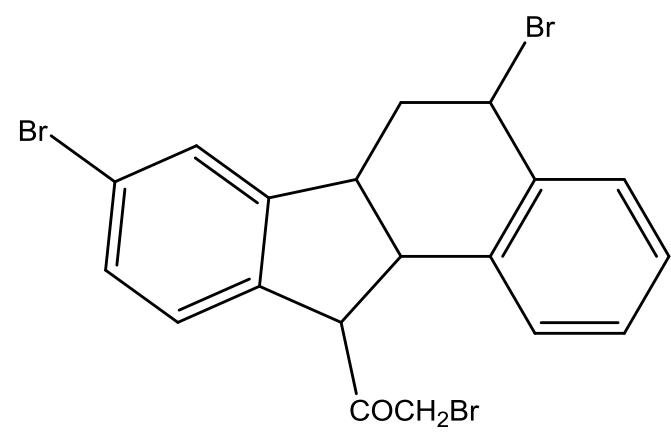

(10)

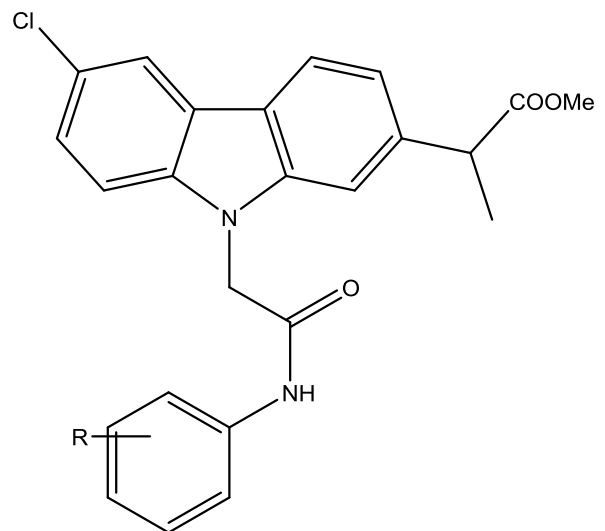

$\mathrm{R}=$ (a) $\mathrm{p}-\mathrm{OCH}_{3}$, (e) p-Br, (g) 2,6- $\mathrm{DiCH}_{3}$, (h) p- $\mathrm{CH}_{3}$ 


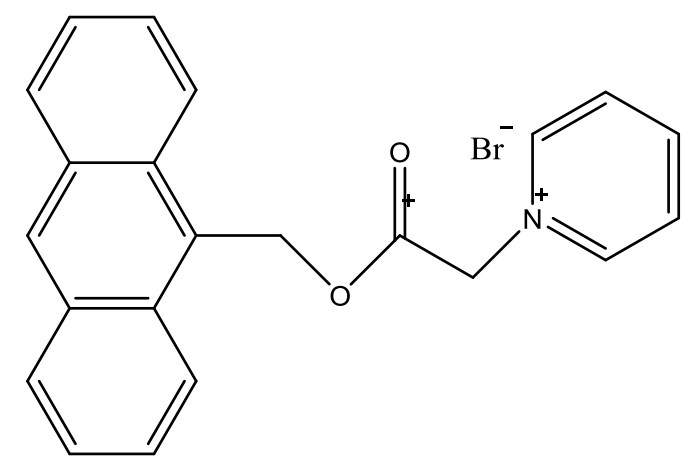

(13)

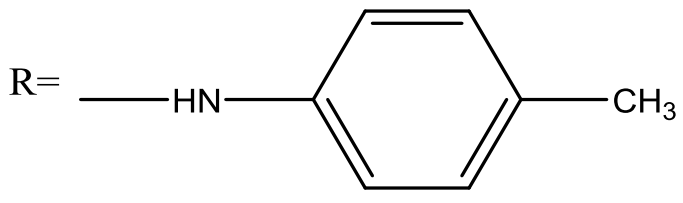

(15)

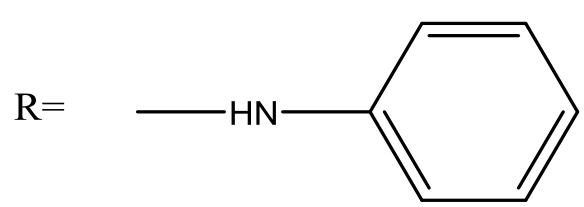

(14)

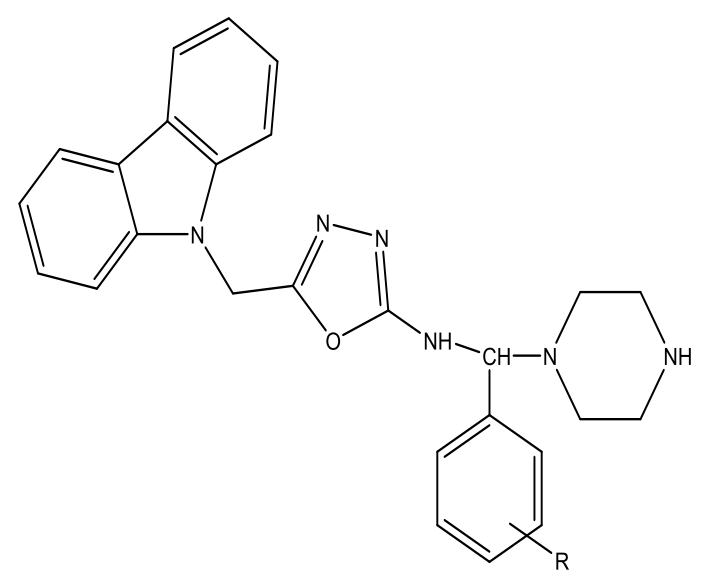

(16)

$\mathrm{R}=(\mathrm{a}) p$-nitro, (d) $p$-chloro, (e) $p$-(dimethylamino), (n) $p$-Flouro<smiles>[R]C1NC2Nc3ccccc3C2N1NCC(=O)Cn1c2ccccc2c2ccccc21</smiles>

(17) 

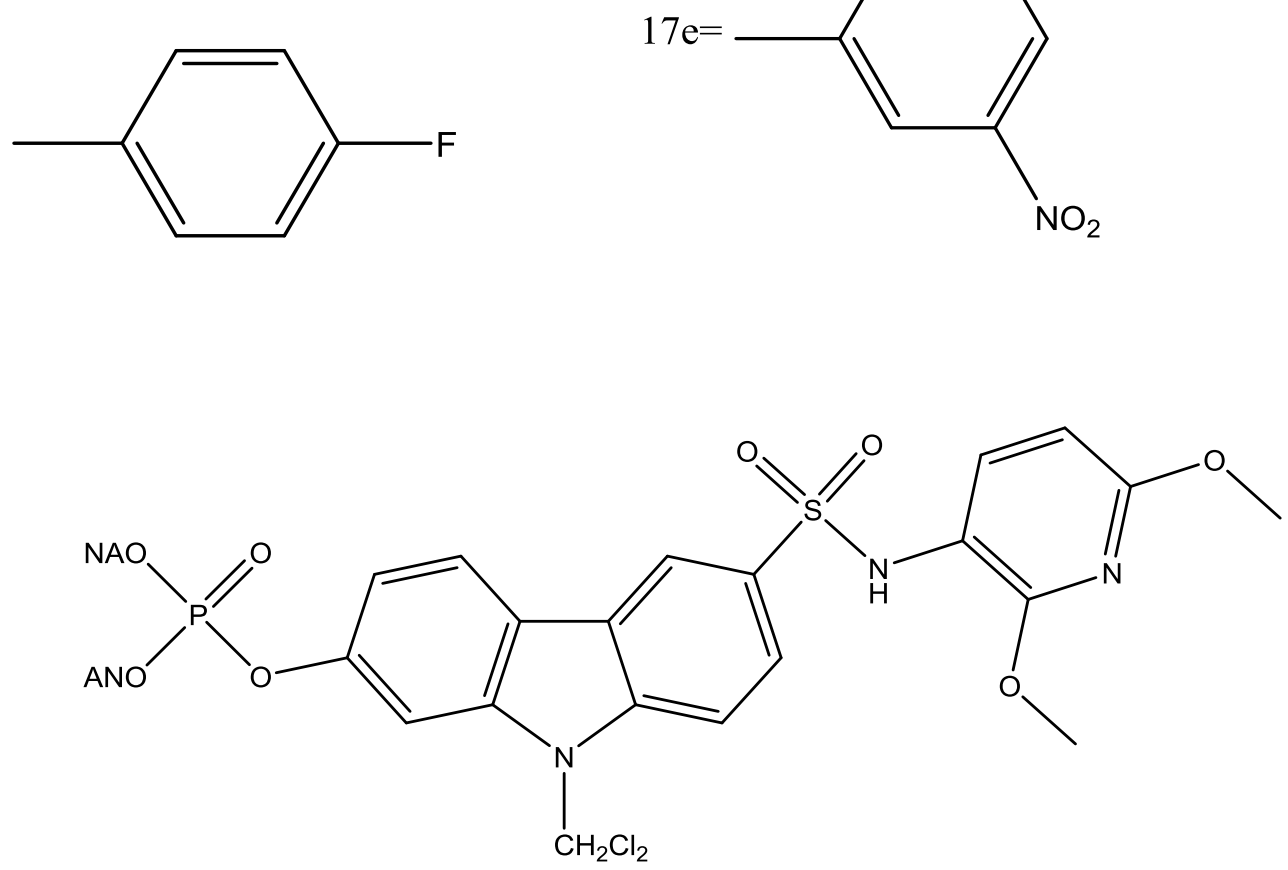

(18)

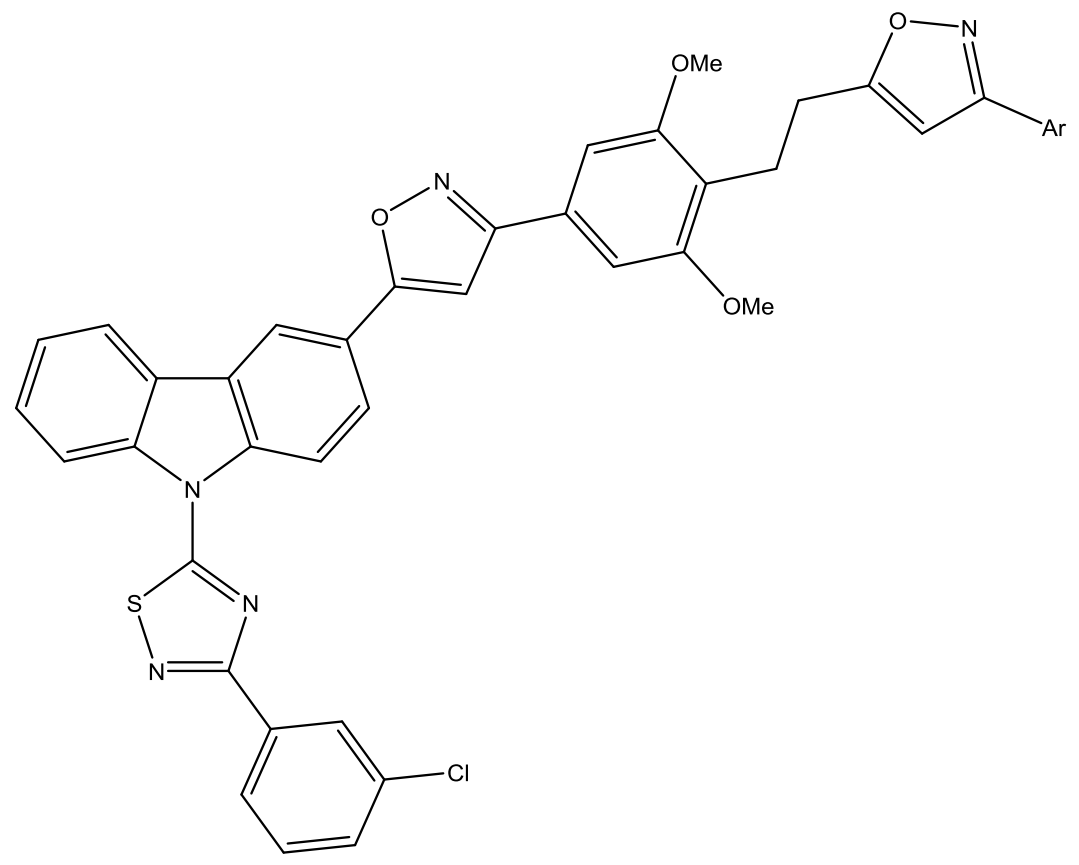

(19)

19b=2,4-dimethoxyphenyl, 19c=2,3-dimethoxyphenyl, 19f=pyridine-4-yl, $19 \mathrm{~g}=$ =pyrrol-2-yl 


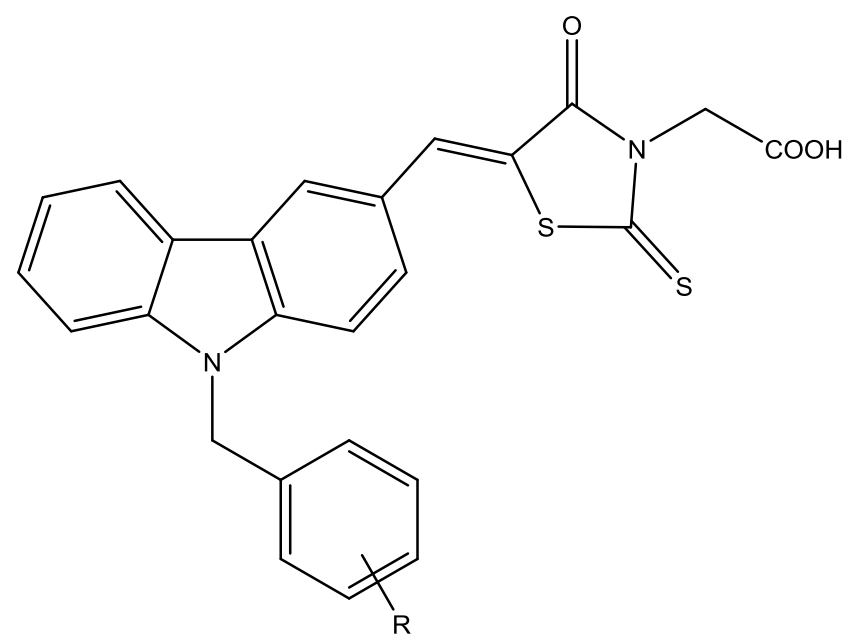

R- $a=2-f, 4-B r, b=4-N_{2} \quad g=4-C N$

(20)
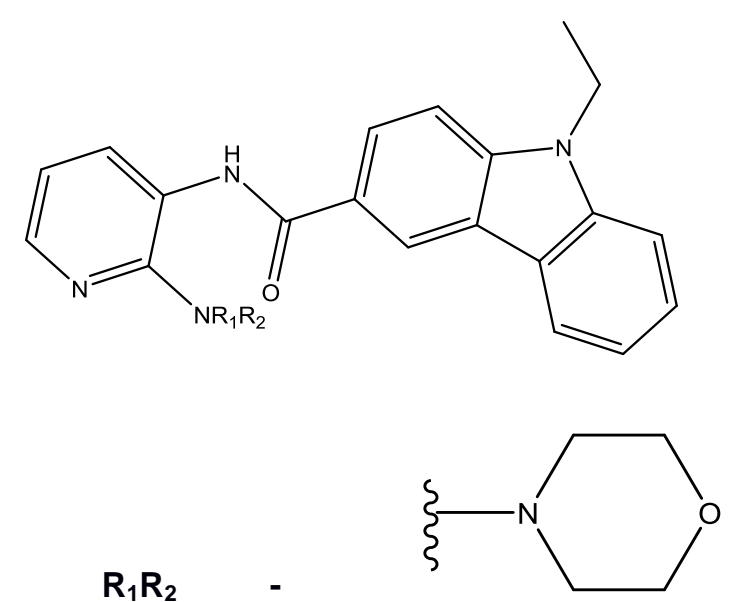

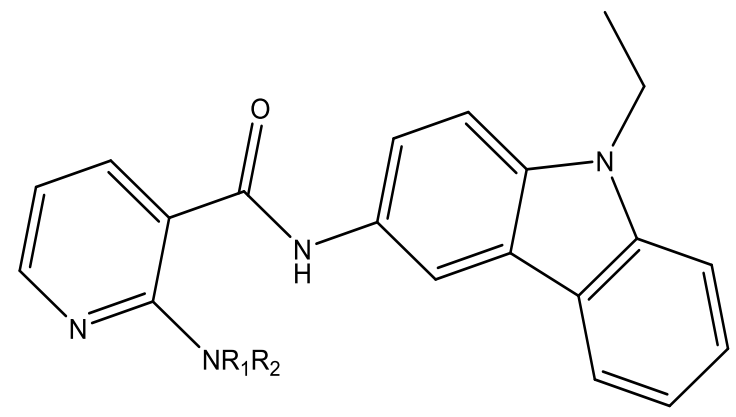

NR1,R2 =

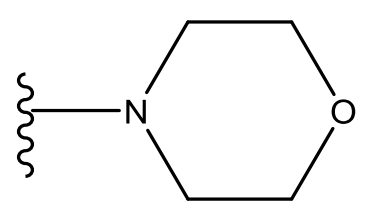

(21)

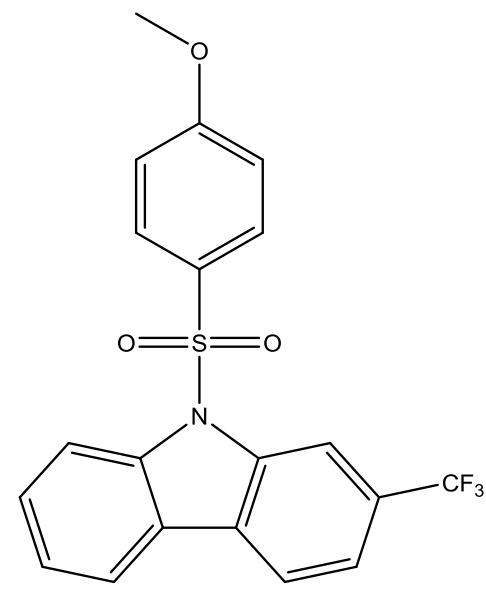

(23)

(22) 


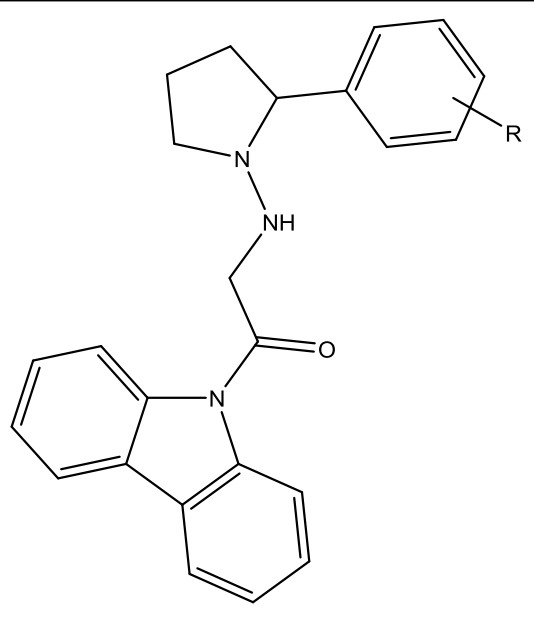

$\mathbf{R =}$ 4-dimethylamino

(24)

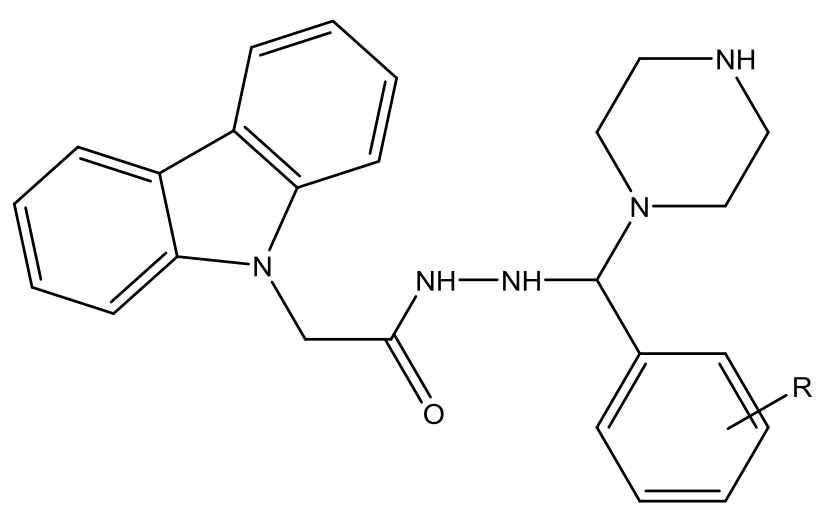

R= 4-dihydroxy

(25)<smiles></smiles><smiles></smiles>

$\mathrm{X}=\mathrm{N}-\mathrm{Me}, \quad \mathrm{Y}=$<smiles>CC(C)(C)CCN1CCCC1</smiles>

(26)

Ar= 5-Hydroxyphenyl

(27) 


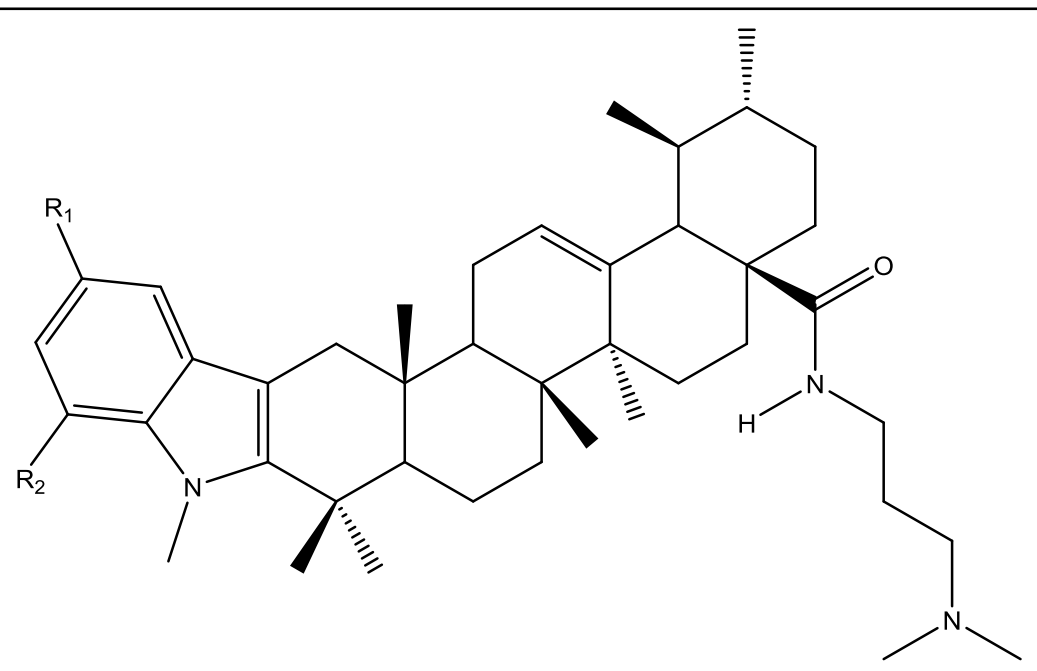

$\mathbf{R}_{\mathbf{1}}=\mathbf{C H}_{3}, \mathbf{R}_{\mathbf{2}}=\mathbf{H}$

(28)

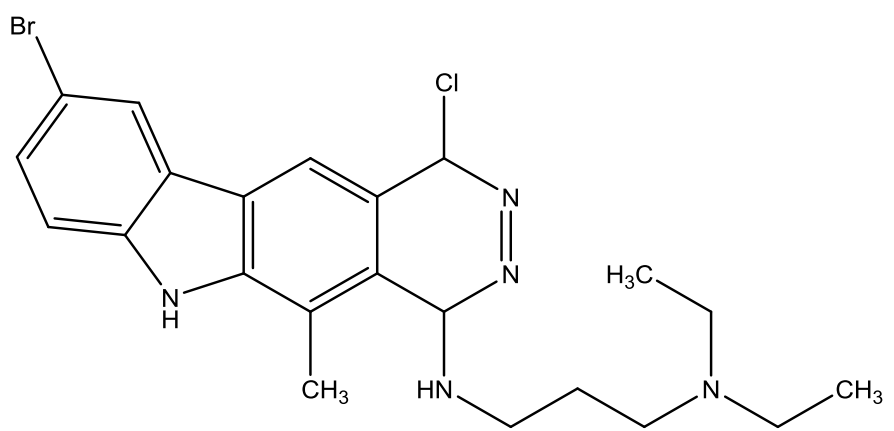

(29)

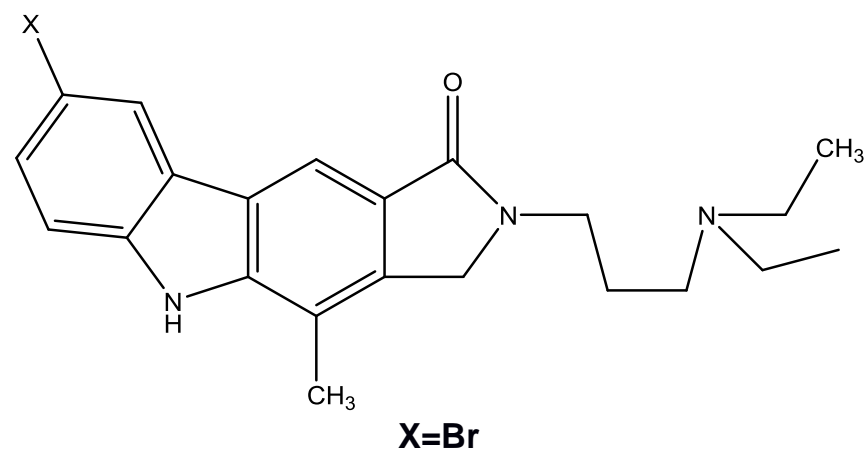

(30) 


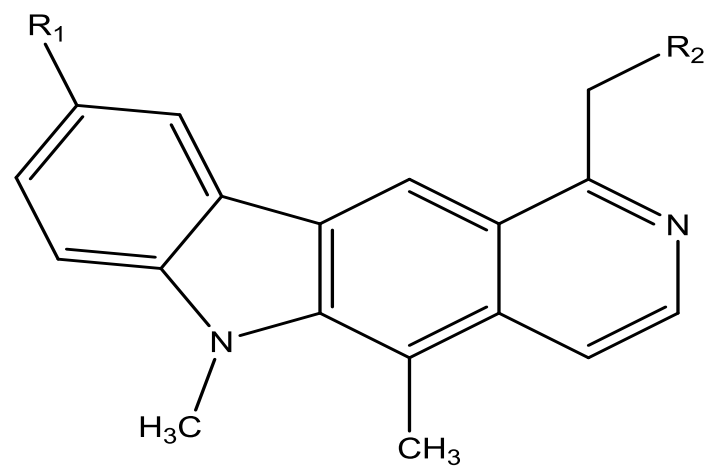

(31) $\mathrm{R}_{1}=\mathrm{OH}, \mathrm{R}_{2}=\mathrm{NHCH}_{2} \mathrm{CH}_{2} \mathrm{OH}$

(32) $\mathbf{R}_{1}=\mathrm{OMe}, \mathrm{R}_{2}=\mathrm{CH}_{2} \mathrm{NHCCH}_{2} \mathrm{CH}_{3}\left(\mathrm{CH}_{2} \mathrm{OH}\right)$

(33) $\mathbf{R}_{1}=\mathrm{OH}, \mathrm{R}_{2}=\mathrm{NHC}\left(\mathrm{CH}_{3}\right)_{2} \mathrm{CH}_{2} \mathrm{OH}$

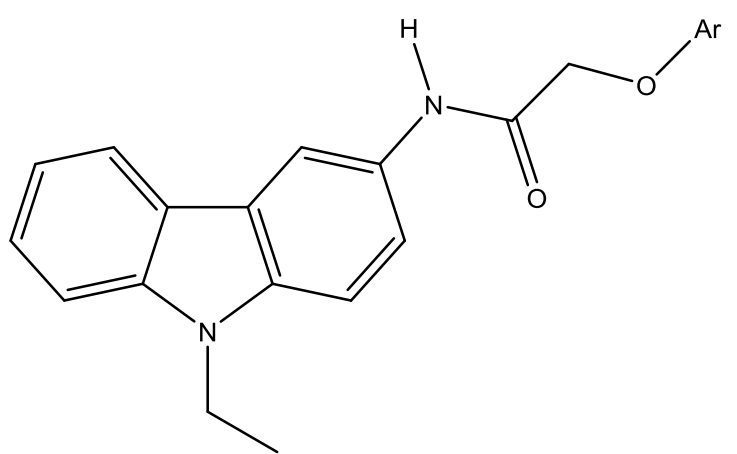

(34a) Ar= 2-Methylphenyl

(34c) Ar=4-Ethylphenyl

(34e) $\mathrm{Ar}=4$-chlorophenyl

(34j) Ar=3,4-Diethylphenyl

(34i) Ar=3,5-Dimethylphenyl

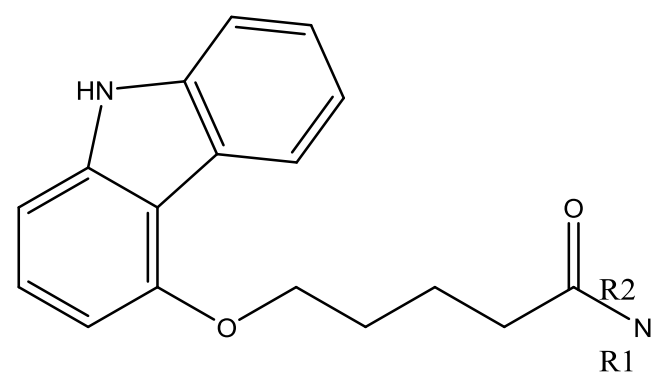

(35)

(35A) $\mathbf{R}^{1}=$ Hydrogen, $\mathbf{R}^{2}=$ Thiophene-2-ethyl (35b) $\mathbf{R}^{1}=$ Hydrogen, $\mathbf{R}^{2}=$ Prop-2-yl

(35c) $\mathrm{R}^{1}=1$-(Morpholinyl 


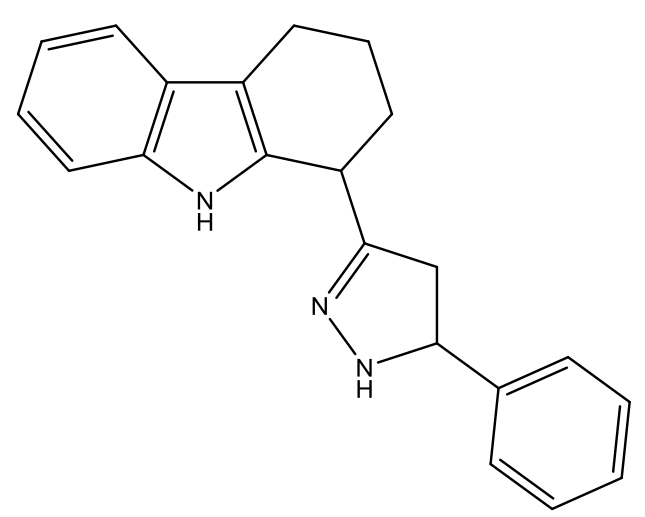

(36)
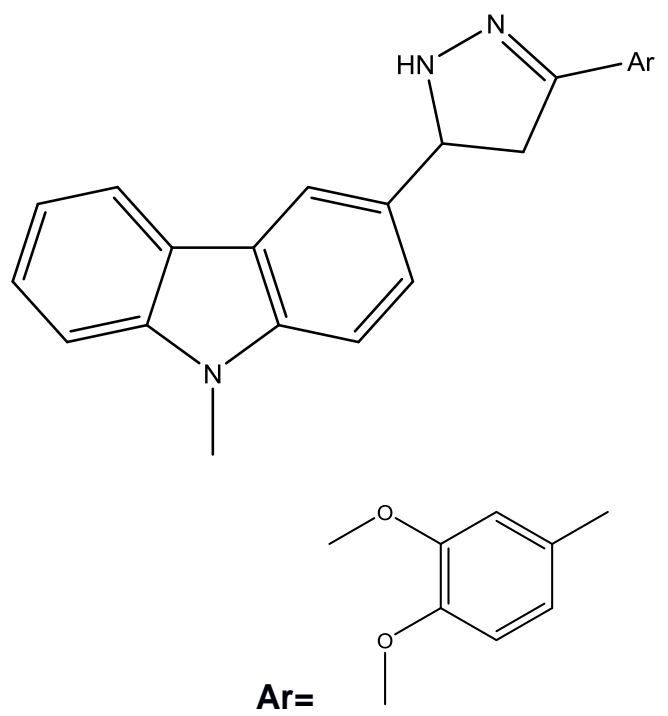

(38)

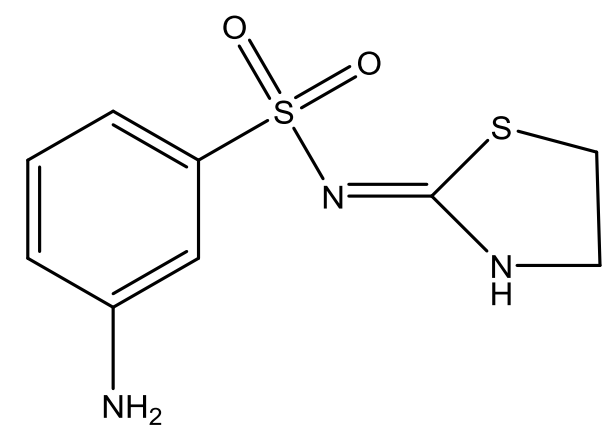

(40)

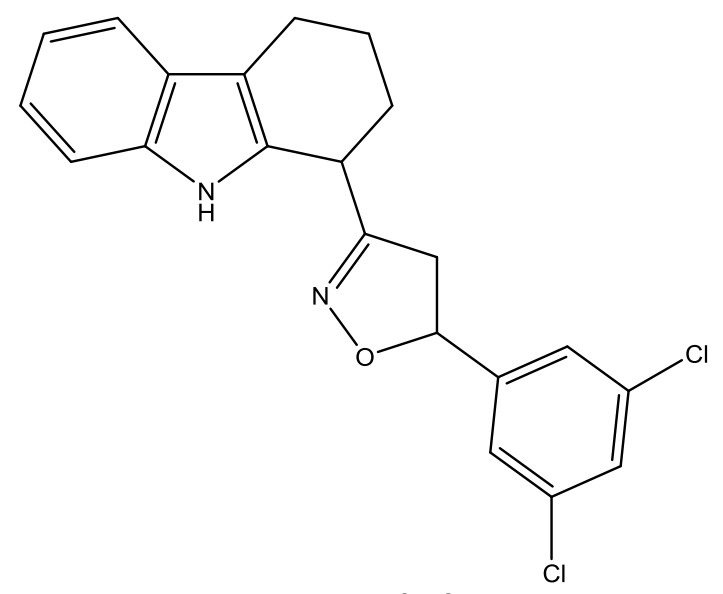

(37)

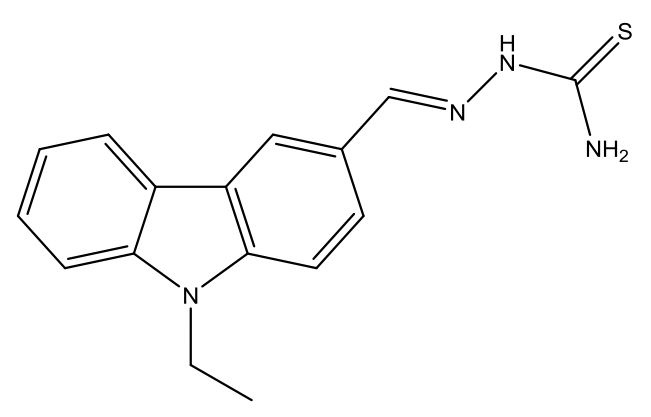

(39)

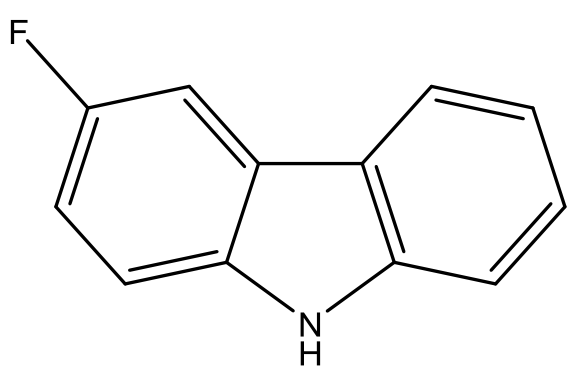

(41) 


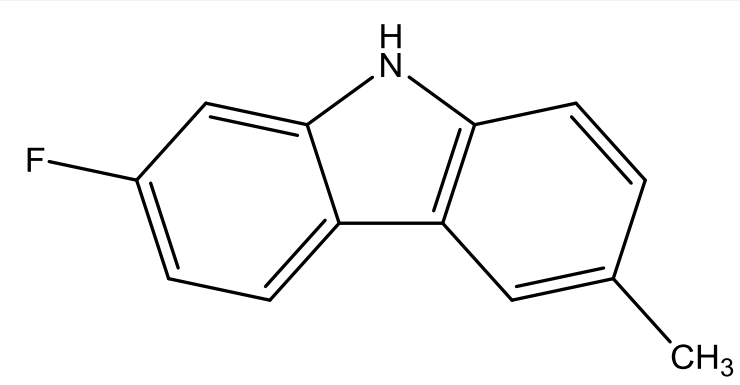

(42)

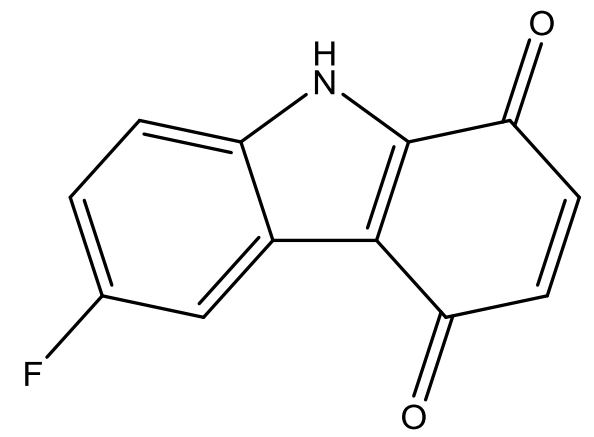

(44)

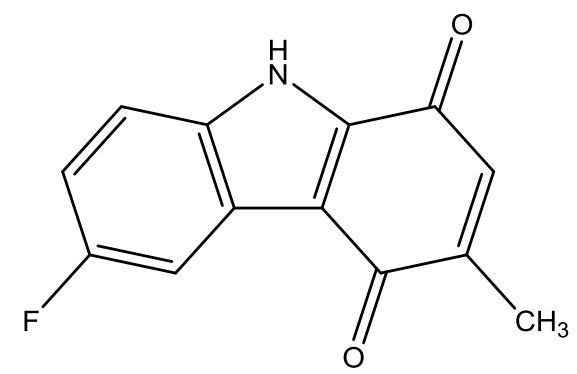

(46)<smiles>Cc1ccc2c(c1)[nH]c1cc(F)ccc12</smiles>

(43)

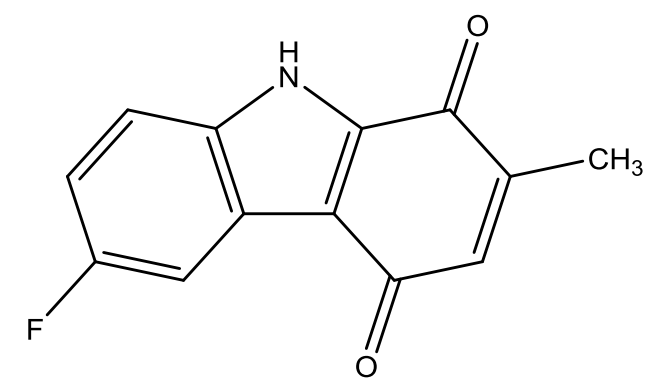

(45)

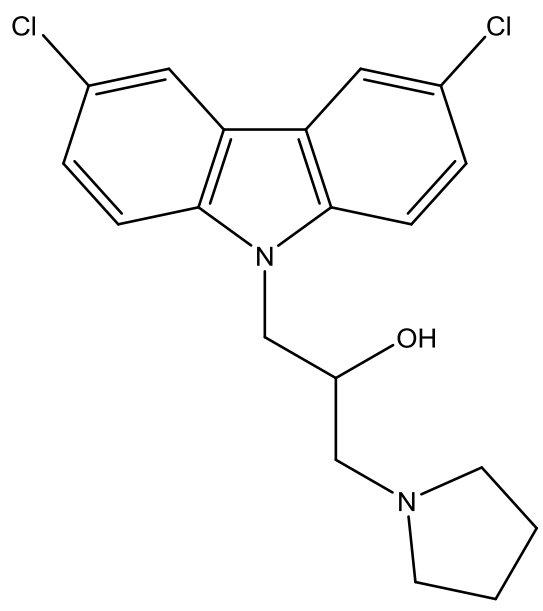

(47) 


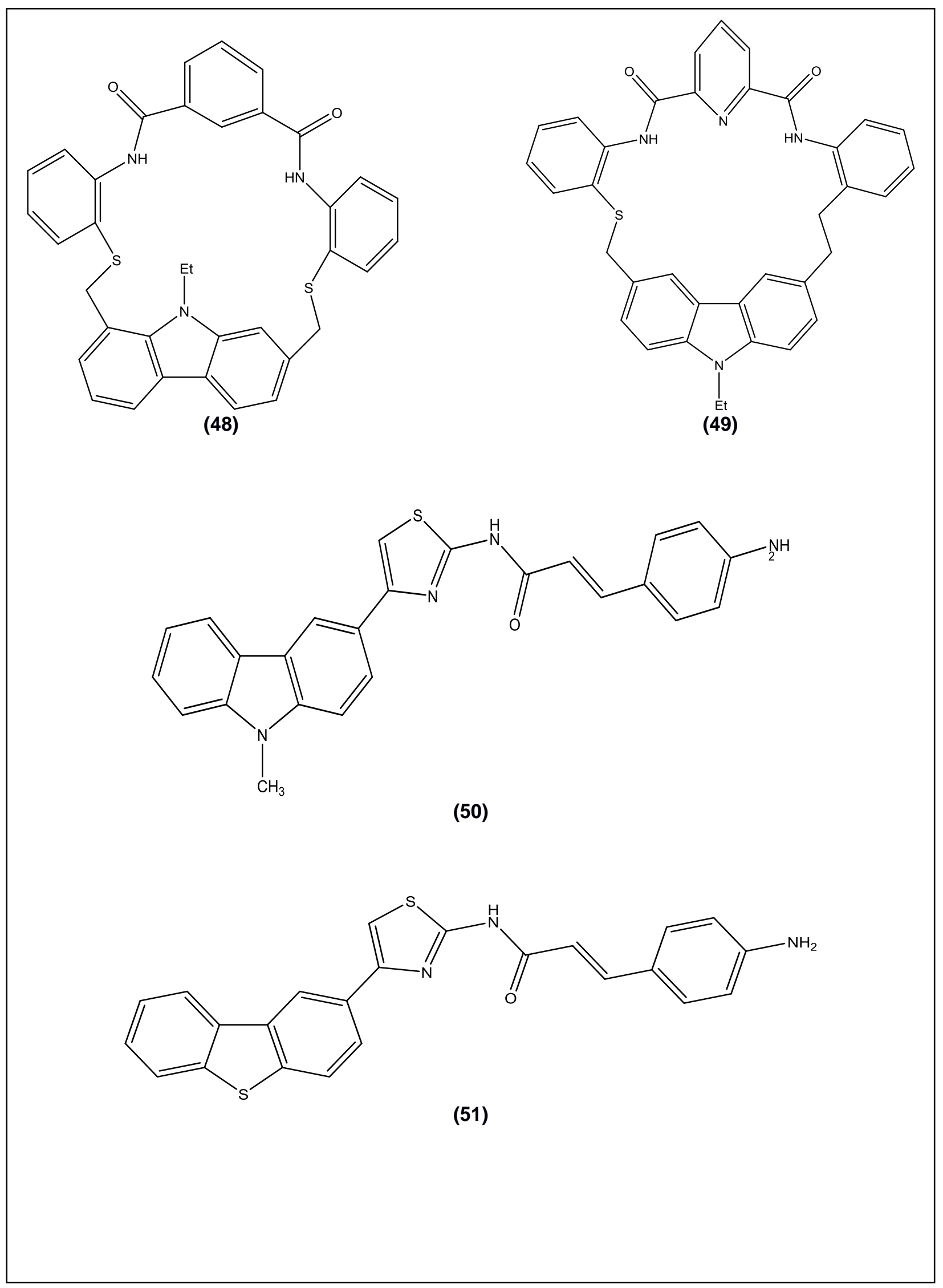




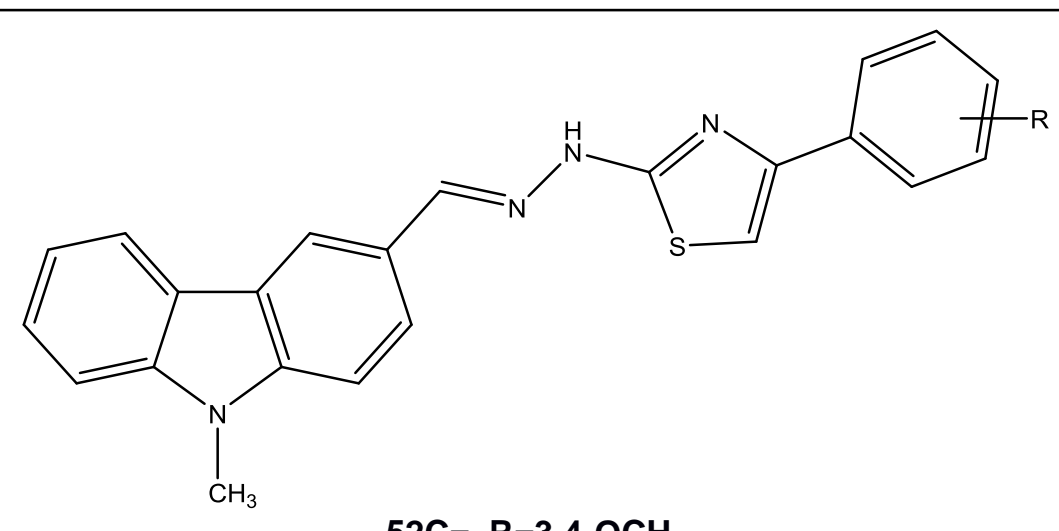

(52)

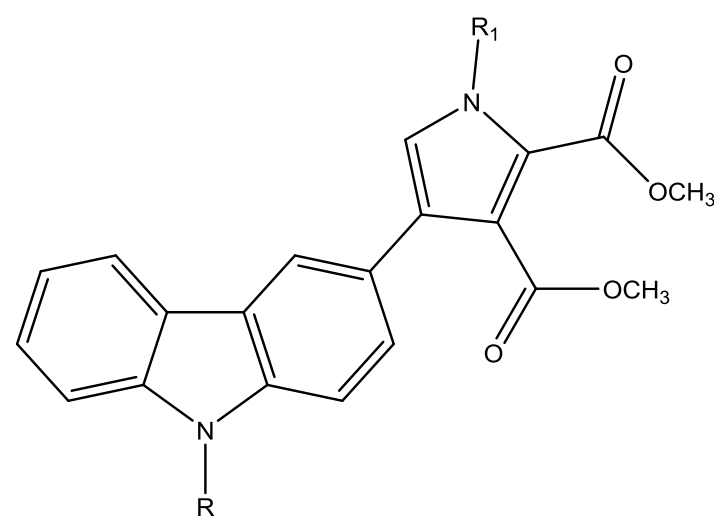

(53)
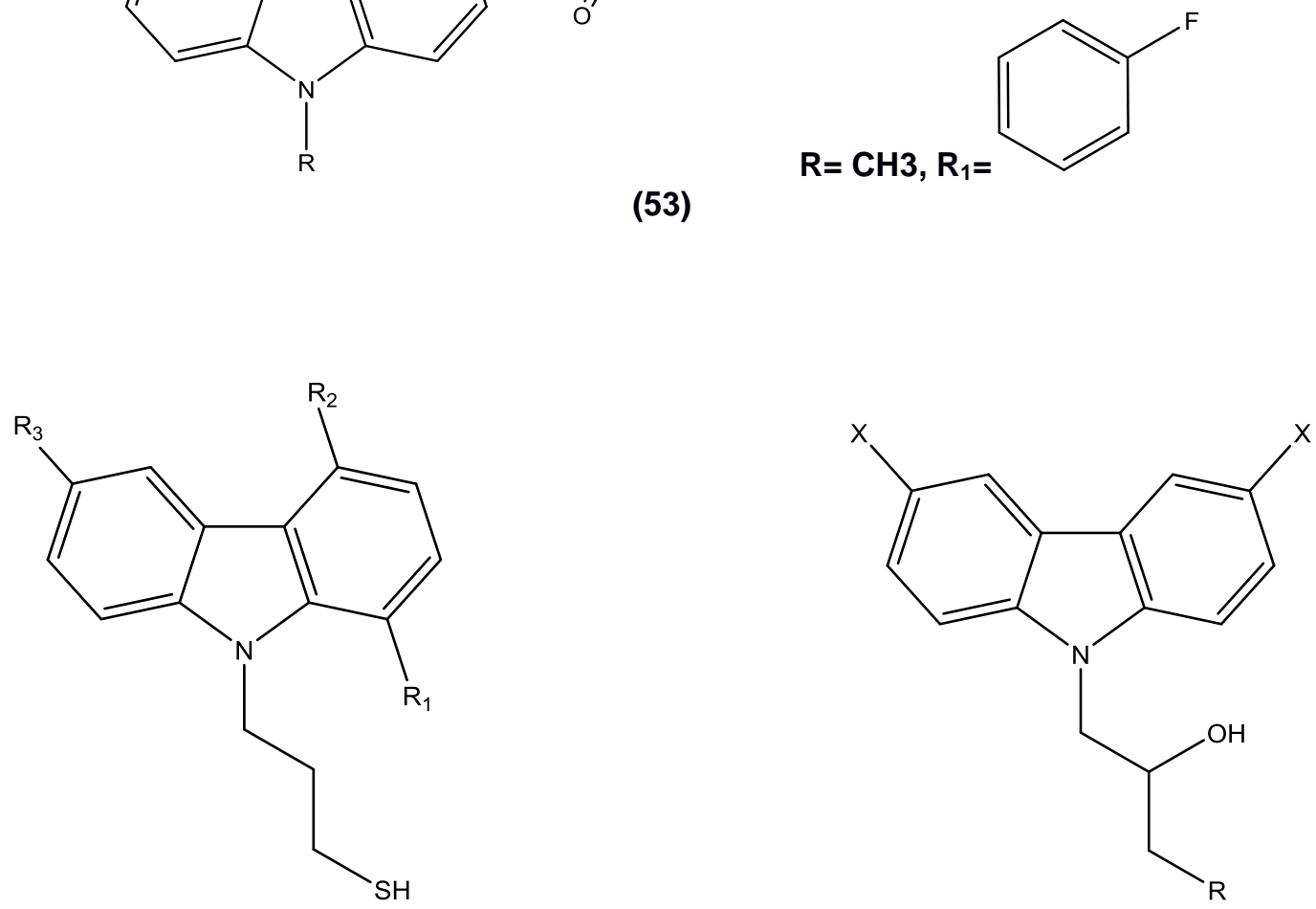

$\mathbf{R}_{1}=\mathbf{R}_{2}=\mathbf{C H}_{3}, \mathbf{R}_{3}=\mathrm{Br}$

(54)

$\mathrm{X}=\mathrm{Cl}, \quad \mathrm{X}$

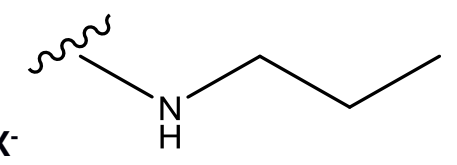

(55) 


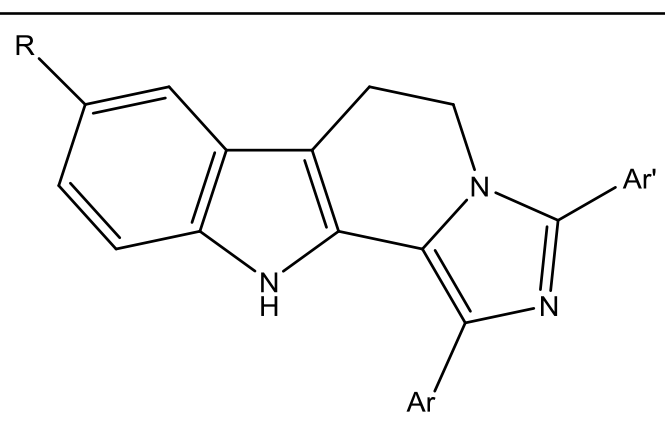

$(56-0) R=H, A r=$<smiles>[Te]=Cc1ccccc1</smiles>

(56-v) $\mathrm{R}=\mathrm{OCH}_{3} \mathrm{Ar}=$<smiles>Cc1ccc(Br)cc1</smiles><smiles>[Te]=Cc1ccccc1</smiles>

(56)

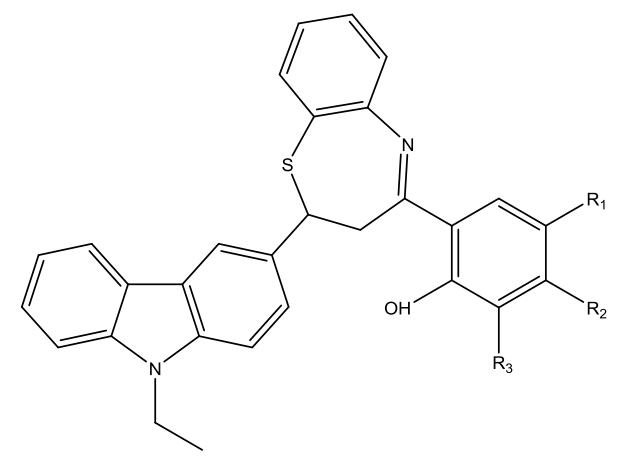

(57)

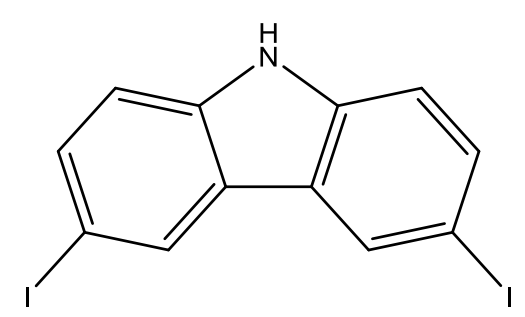

(58)

$57 \mathrm{a}=\mathrm{R}_{1}=\mathrm{Cl}, \mathbf{R}_{2}=\mathrm{H}, \mathrm{R}_{3}=\mathrm{Cl}$

$57 \mathrm{~b}=\mathrm{R}_{1}=\mathrm{Cl}, \mathrm{R}_{2}=\mathrm{H}, \mathrm{R}_{3}=\mathrm{H}$

$\mathbf{5 7 d}=\mathbf{R}_{\mathbf{1}}=\mathrm{Br}, \mathbf{R}_{\mathbf{2}}=\mathrm{H}, \mathbf{R}_{\mathbf{3}}=\mathrm{H}$ 


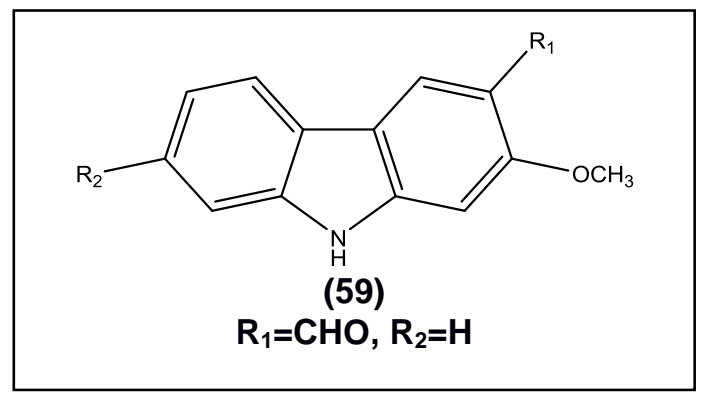

\section{REFERENCES}

1. Beliers M, Sartor V, Fabre PL, Poteau $R$, Bordeau $G$ and Lalanne NC. Simple electron donar molecules based on triphenylamine and carbazole derivatives. Dyes and Pigments. 2018; 153:275-283.

2. Bashir $M$, Bano $A$, ljaz $A S$ and Chaudhary BA. Recent developments and biological activities of $\mathrm{N}$ substituted carbazole derivatives: A Review. Molecules. 2015;20:1349613517.

3. Kaplancikli ZA. Synthesis of some novel carbazole derivatives and evaluation of their antimicrobial activity. Pharma J. 2011;15:105-109.

4. Kaushik K, kumar N and Pathak D. Docking, synthesis and anticancer activity of some newer carbazole derivatives. International J. of pharma. Chem. 2012;4:470-478.

5. Kadam ML, Patil D and Sekar N. Fluorescent carbazole based pyridine dyes-synthesis, solvatochromism, linear and non linear optical properties. Optical Material. 2018;85:308-3018.

6. Bashir M, Bano A, ljaz AS and Chaudhary BA. Recent developments and biological activities of $\mathrm{N}$ substituted carbazole derivatives: A Review Molecules. 2015;20:1349613517.

7. Zhang FF, Gen LL and Zhou CH. Synthesis, antibacterial and antifungal activities of some carbazole derivatives. Bioorg. Med Chem Lett. 2010;20:1881-18884.

8. Balouiri M, Sadiki M and Ibnsouda SK. Methods for in vitro evaluating antimicrobial activity: A review. J. of Pharm. Analysis. 2016;6:71-79.

9. Ryan A, Tuffy B, Horn S, Blau WJ and Senge MO. Tetrahedron. 2011;67:8348-8254.

10. Rice NA and Adronov A. Macromolecules. 2013;46:3850-3860.
11. Won $C$ and Lee JY. Dyes pigments. 2014;103:34-38.

12. Songsiang $U$, Thongthoom $T$, Boonyarat C and Yenjai C. Nat Prod. 2011;74:208-212.

13. Ma $Q$, Tian J, Yang $A$, Wang $T \mathrm{Ji}$, Wang $Y$ and Su Y. Fitoterapia. 2013;87:1-6.

14. Mahapatra DK, Bharti SK and Asati V. Eur J Med Chem. 2015;98:69-114.

15. Saravanabhavan $M$, Sathya VG , Puranik $M$ and Sekar. Spectochim Acta A Mol. Biomol Spectrosc. 2014;118:399-406.

16. Molette J, Routier J, Alba N, Besson D, Bombrun A, Brun R, Burt H, Georgi $\mathrm{K}$, Kaiser M, Nwaka S, Muzerelle M and Scheer A. ACS Med. Chem Lett. 2013;4:1037-1041.

17. Bandgar BP, Adsul LK, Chavan HV, Jalde SS, Shringare S, Shaikh R, Meshram RJ, Gacche RN and Masand V. Bioorg Med Chem Lett. 2012;22:5839-5844.

18. Zall A, Kieser D, Hottecke N, Naumann EC, Thomaszewski B, Schneider K, Steinbacher DT, Schubenel R, Masur S, Baumann K and Schmidt B. Bioorg Med Chem. 2011;19:4903-4909.

19. Thiratmatrakul $S$, Yenjai $C$, Waiwut $P$, Vajragupta $O$, Reubroycharoen $P$, Tohda M and Boonyarat C. Eur J Med Chem. 2014;75:21-23.

20. Macmillan KS, Naidoo J, Liang J, Melito L, Williams NS, Morlock L, Huntington PJ, Estill SJ, Longgood J, Becker GL, Mcknight SL, Piper AA, Brabander JK and Ready JM. J Am Chem Soc. 2011;133:1428-1437.

21. Choubdar N, Golshani M, Baleh L, Nadri H, Kucukkilinc T, Ayazgok B, Moradi A, Mogdhadam FH, Abdolahi $Z$, Aeri A, Salehian F, Foroumadi A and Khoobi M. New class of carbazoles as potential multifunctional anti-Alzheimer's agents. Bioorg Med Chem. 2019;91:1-10. 
22. Ghobadian R, Nadri H, Moradi A, Bukhari SNA, Mahadevi M. Asadi M, Akbarzadeh, T, Sharifzadeh $M$ and Amini M. Design, synthesis and biological evaluation of selective and potent carbazole-based butyrylcholinesterase inhibitors. Bioorg med Chem. 2018;8:1-26.

23. Dabrovolskas K, Jonuskiene I, Sutkuviene $S$ and Gudeika D. Synthesis and evaluation of antibacterial and antioxidative activities of carbazole derivatives. Chemmija. 2020;31:42-51.

24. Venkatapathy K, Magesh CJ, Lavanya G, Perumal PT and Prema S. Design, synthesis, molecular docking, and spectral studies of new class of carbazolylpolyhydroquinoline

derivatives as promising antibacterial agents with noncytotoxicity towards human mononuclear cells from peripheral blood. J. Heterocyclic Chem. 2020;57:1-20.

25. Guhanathan S, Murugesan MS and Sangeetha U. Investigation of dibromo and N-bromoacetyl derivatives of [b] carbazole-synthesis and antibacterial evaluation. International $\mathrm{J}$ of $\mathrm{New}$ Chem. 2019;6:66-75.

26. Pattanashetty SH, Hosamani KM, Shettar AK and Shafeeulla RM. Design, synthesis and computational studies of novel carbazole $\mathrm{N}$ phenylacetamide hybrid as potent antibacterial, anti-inflammatory, and antioxidant agents. $\mathrm{J}$ Heterocyclic Chem. 2018.

27. Wang PY, Fang HS, Shao WB, Zhou $J$, Chen Z, Song BA and Yang S. synthesis and biological evaluation of pyridinium-functionalized carbazole derivatives as promising antibacterial agents. Bioorg. Med. Chem. Lett. 2017; 27: 4294-4297.

28. Parthiban P, Alagarsamy V, Narayanan BL, Babu $P$, Singh Hanish JC, Design, synthesis antibacterial and antifungal activity of some substituted tetrahydro carbazole derivatives. International J. of pharmacy and pharmaceutical Analysis. 2014;01:1-8.

29. Sharma D, Kumar N and Pathak D. Synthesis, characterization and biological evaluation of some newer carbazole derivatives. J of the Serbian Chemical Society. 2014;79:125-132.

30. Kaushik K, Kumar N and Pathak D. Synthesis of some newer carbazole derivatives and evaluation for their pharmacological activity. Pelagia Research Library. 2012;3:470-478.

31. Liu Y, Wu Y, Sun L, Gu Y and Hu L. Synthesis and structure-Activity relationship study of water-soluble carbazole sulfonamide derivatives as new anticancer agents. Eur $\mathrm{J}$ of Med Chemistry. 2020;191:1-41.

32. Rao BVD, Sreenivasulu $R$ and Rao MVB. Design, synthesis and evaluation of isoxazole-Thiadiazole linked carbazole hybrids as anticancer agents. Russian $\mathrm{J}$ of General Chem. 2019; 89:2115-2120.

33. Jing $\mathrm{H}$, Zhang WJ, Li $\mathrm{PH}$, Wang J, Dong $\mathrm{CH}$, Zhang $\mathrm{K}$, Chen $\mathrm{HX}$ and Du ZY. Synthesis and biological evaluation of novel carbazolerhodanine conjugates as topoisomerase II inhibitors. Bioorg Med Chem Lett. 2018;28:1320-1323.

34. Vlaar CP, Pichardo LC, Medina JI, Velez E, Ramos Z and Hernandez E. Design, synthesis and biological evaluation of new carbazole derivatives as anti-cancer and antimigratory agents. Bioorg Med Chem. 2018;26:884-890.

35. You X, Zhu D, Lu W, Sun Y, Qiao S, Luo B, Du Y, Pi R, Hu Y, Huang P and Wen $S$. Design, synthesis and biological of $\mathrm{N}$-arylsulfonylcarbazoles as novel anticancer agents. Royal society chem. 2018;8:17183-17190.

36. Kumar N and Pathak D. Design, synthesis and anticancer activity of 9substituted carbazole derivatives. International J. pharma science and research. 2016;8:3291-3298.

37. Li B, Yue Z, Feng J, He Q, Miao ZH and Yang $\mathrm{CH}$. Design and synthesis of pyrido[3,2- $\alpha$ ] carbazole derivatives and their analogues as potent antitumour agents. European $\mathrm{J}$ med Chemistry. 2013;66:531-539.

38. Gu W, Hao Y, Zhang G, Wang SF, Miao TT and Zhang KP. Synthesis, in vitro antimicrobial and cytotoxic activities of new carbazole derivatives of ursolic acid. Bioorg med Chem Lett. 2015;25:554-557.

39. Haider N, Marian B, Nagel T, Tarnai M and Tropper K. Electrophillic substitution of Dimethyl 1Methylcarbazole-2,3-dicarboxylate: Synthesis of new b-Fused carbazoles as potential antitumor agents. J Braz Chem Soc. 2014;25:1965-1974.

40. Howorko RJ, Tylinska B, Biadun B, Gebarowski $T$ and Gasiorowski K. Synthesis of new pyridocarbazole 
derivatives their in vitro anticancer activity. Acta Poloniae Pharmaceutica. 2013;70:823-832.

41. Kaplancikli ZA, Yurttas L, Zitouni GT, Ozdemir A, Ozic R and Yildirim SU. Synthesis, antimicrobial activity and cytotoxicity of some new carbazole derivatives. J enzyme inhibition med Chem. 2012;27:868-874.

42. Muniyappan G, Kathvarayan S, Kella CR, Kalliyappan E, Ponnusamy S and Thirumalai $P$. Synthesis of novel 4hydroxycarbazole derivatives and evaluation of their in vitro antiinflammatory, antioxidant activities and molecular docking. Research on Chem. Intermediates. 2016;43:1-17.

43. Surendiran T. Studies on antiinflammatory behaviour of chalconyl, isoxazolinyl and pyrazolinyl 1,2,3,4tetrahydrocarbazoles. international $\mathrm{J}$. pharma tech research. 2018;8:183188.

44. Bandgar BP, Adsul LK, Chavan HV, Jalde SS, Shringar SN, Shaikh R, Meshram RJ, Gacche RN and Masand V. Synthesis, biological evaluation, and docking studies of 3-(substituted)aryl-5-(9-methyl-3-carbazole)-H-2-

pyrazolines as potent antiinflammatory and antioxidant agents. Bioorg Med Chem Lett. 2012;22:58395844.

45. Jasass RS, Alshehrei $F$ and Farghaly TA. Microwave- Assisted Synthesis of Antimicrobial agents containing carbazole and thiazole moieties. J. Hetrocyclic Chem. 2018;55:1-8.

46. Chakraborty S, Saha A, Saha C, Ghosh TK and Bhattacharyya I. Evaluation of antimicrobial activity of synthesized fluorocarbazole derivatives based on SAR. Indian $\mathrm{J}$ of chem. 2017; 56B:701-708.

47. Clausin JD, Kjellerup L, Cohrt KO, Hansan JB, Brown WD and Winther AM. Eluciation of antimicrobial activity and mechanism of action by $\mathrm{N}$ substituted carbazole derivatives. Bioorg Med Chem Lett. 2017;27:45644570.

48. Gluszynsk A. Biological potential of carbazole derivatives. European J med Chem. 2015;91: 405-426.

49. Surinei G, Marvadi SK, Yogeeswari PS, Sriram D and Kantevari. Dibenzofuran, dibenzothiophene and N-methyl carbazole tethered 2aminothiazoles and their cinnamamides as potent inhibitors of mycobacterium tuberculosis. Bioorg Med chem Lett. 2018;28:1610-1614.

50. Shaikh MS, Palkar MB, Patel HM, Rane R, Alwan W, Shaikh M, Hampannavar $G$ and Karpoormath $R$. Design and synthesis of novel carbazolo-thiazoles as potential antimycobacterial agents using a molecular hybridization approach. Royal soceitychem. 2014;4: 6230862320.

51. Surinei G, Marvadi SK, Yogeeswari $P$, Sriram D and Kantevari. Design and synthesis of novel carbazole tethered pyrrole derivatives as potent inhibitors of mycobacterium tuberculosis. Bioorg Med chem Lett. 2015;25:485-491.

52. Sinicropi MS, Lacopetta D, Rosano C, Randino R, Caruso A, Saturmino C, Muia N, Ceramella J, Puoci F, Rodriquez $\mathrm{M}$ and Plutino. $\mathrm{N}$ thioalkylcarbazoles derivatives as new anti-proliferative agents: synthesis, characterization and molecular mechanism evaluation. J enzyme Inh Med Chem. 2018;33:434-444.

53. Wang $W$, Sun $X$, Sun D, Li S, Yu Y, Yang T, Yao J, Chen $Z$ and Duan L. Carbazoleaminoalcohols induce antiproliferation and apoptosis of human tumor cells by inhibiting topoisomerase I. Chemical med chem. 2016;11:1-8.

54. Adib M, Peytam F, Shourgeshty R, Khanaposhtani M, Jahani $M$, Imanparast S, Faramarzi MA, Larijani $B$, Moghadamnia AA, Esfahani EN, Bandarian $F$ and Mahdavi M. Design and synthesis of new fused carbazoleimidazole derivatives as anti-diabetic agents: In vitro $\alpha$ - glucosidase inhibition, kinetic, and in silico studies. Bioorg Med Chem Let. 2019;29:713718.

55. Shelke SN and Kadnor VA. Synthesis, antimalarial activity of 1,4benzothiazepine and pyrazoline derivatives incorporating carbazole moiety. Bulgarian chemical communications. 2019;51:234-241.

56. Dabrovolskas K, Jonuskiene I, Sutkuviene $S$ and Gudeika D. Synthesis and evaluation of antibacterial and antioxidative activities of carbazole derivatives. CHEMIJA. 2020;31:42-51.

57. Caruso A, Ceramelle J, Lacoptta D, Saturnino C, Mauro MV, Bruno R, Aquaro $S$ and Sinicropi MS. Carbazole derivatives as antiviral agents: An overview. Molecules. 2016;24:1-23. 